\title{
Improvement of Mesoscale Forecasts of Monsoon Depressions Through Assimilation of QuikSCAT Wind Data: Two Case Studies Over India
}

\author{
P.K. Sinha ${ }^{1}$ and A. Chandrasekar ${ }^{*}, 2$ \\ ${ }^{I}$ Department of Physics \& Meteorology, Indian Institute of Technology Kharagpur, Kharagpur, Pin - 721302, India \\ ${ }^{2}$ Indian Institute of Space Science and Technology, Department of Space, Government of India, Thiruvananthapuram, \\ Pin - 695 022, India
}

\begin{abstract}
Monsoon depressions form during the Southwest Indian Monsoon over the Bay of Bengal and provide copious rainfall over the eastern and central parts of the country. Since these depressions form over sea, a region of data scarcity, satellite data provides only source of information of the meteorological system. Furthermore, for short-range prediction, it is extremely important to have accurate initial conditions for better model performance. In this study, effects of three dimensional variational (3DVAR) assimilation of the Quick Scatterometer (QuikSCAT) data is used in the simulation of two monsoon depressions (MDs) that formed during 2-5 September and 27-30 September 2006 using the Weather Research and Forecast (WRF) modeling system. The National Center for Environmental Prediction - Global Forecast (NCEP-GFS) fields were used for the initial and lateral boundary conditions. Two model runs were employed in this study; first a control (CTRL) or a base run without any data assimilation and another a 3DVAR run in which QuikSCAT data was assimilated using the 3DVAR assimilation. The model results from both runs were compared with one another as well as with Tropical Rainfall Measurement Mission (TRMM) observations and Global Analysis (GFS-ANL) fields. The results of the time and area averaged vertical profile of relative vorticity over monsoon depressions indicate that the 3DVAR run is in closer agreement with GFS-ANL as compared to the CTRL run. Furthermore, the well-known temperature structure of a monsoon depression (cold core at low levels and warm core at upper levels) is better simulated by the 3DVAR run. While there is a clear and marked positive impact of ingesting the QuikSCAT data in terms of simulated precipitation for the depression that formed during 27-30 September 2006, improvement in the simulated rainfall due to QuikSCAT assimilation is slight for the other depression that formed during 2-5 September 2006. Consistent with the above observations, there is a clear improvement in the quantitative measures of the skill scores with lower bias, lower false alarms and higher probability of detection for almost all rainfall thresholds for the model runs which have assimilated the QuikSCAT observations.
\end{abstract}

Keywords: Data assimilation, 3DVAR, WRF, QuikSCAT, Monsoon depression, Bay of Bengal, GFS fields, TRMM observations.

\section{INTRODUCTION}

\subsection{Monsoon Depression (MD)}

Monsoon depressions can be described as weak cyclonic disturbances within the monsoon trough that form over the Bay of Bengal during the Indian summer monsoon season and generally move west-northwestward over the Indian subcontinent [1]. Monsoon depressions are characterized by (i) a large size, where the outermost closed isobar may have a diameter on the order of $1000 \mathrm{~km}$; (ii) a loosely organized cluster of deep convective elements, which may form an elongated band of deep convection; (iii) a low-level wind distribution that has a $200 \mathrm{~km}$ diameter light-wind core, which may be surrounded by a band of gales or contain a highly asymmetric wind field; (iv) lack of a distinct cloud system center, and (v) presence of cold core in lower troposphere and warm core in mid/upper troposphere [1]. Monsoon depressions may further develop to deep depressions by eventually acquiring persistent central convection

*Address correspondence to this author at the Indian Institute of Space Science and Technology, Department of Space, Government of India, Thiruvananthapuram, Pin - 695 022, India; Tel: 91-471 2563483/91-471 2332345; Fax: 91-471 2564806; E-mail: chandatmos@gmail.com and accelerated core winds. Monsoon depressions usually bring copious rain to eastern coasts of India, central parts of India, Bay of Bengal as well as areas from western Thailand to eastern Pakistan.

A large part of the monsoon rainfall over the eastern and central plains of India is associated with low pressure systems, especially, monsoon depressions; hence monsoon depressions need to be better understood and simulated [2]. However, the above still remains a challenging task to simulate realistically these low pressure systems and depressions and their associated spatial and temporal distribution of rainfall by using available mesoscale models [3]. For the short-range prediction, it is extremely important to have accurate initial conditions for better model performance because all the mesoscale models, in general, are very sensitive to the small perturbations in the initial fields and errors in model-predicted fields are due to errors in the initial conditions as well as deficiencies in the model physics [4]. Since monsoon depressions form over sea, a region of data scarcity, data obtained from non-conventional observations such as satellites provides the sole source of information of the meteorological system. In this regard, data assimilation plays a vital role in obtaining the accurate initial state in the numerical atmospheric and oceanic models [5]. 
The Weather Research and Forecast (WRF) ThreeDimensional Variational (3DVAR) system, is a newly developed variational data assimilation system described in Skamarock et al. (2005) [6]. Barker et al. (2003) and Barker et al. (2004) describe in detail the 3DVAR algorithm [7] [4]. The 3DVAR system is capable of successfully analyzing observations from different sources, including those from radiosonde, wind profilers, surface stations, and Doppler radars [8]. Convective schemes of the fifth-generation Mesoscale Model (MM5) and the WRF under the 3DVAR assimilation indicated a weakening for MM5 and strengthening for WRF of observed cross equatorial flow over southern Arabian Sea during simulations [9]. The MM5 showed larger forecast errors in predicted wind, temperature and humidity at different levels compared to those from the WRF. In addition, the simulated rainfall pattern and prediction skill by the WRF was better than those by the MM5.

\subsection{The Data Assimilation Problem}

A data assimilation system combines all available information on the atmospheric state in a given time-window to produce an estimate of atmospheric conditions valid at a prescribed analysis time [4]. Information used to produce the analysis includes observations, previous forecasts (the background or first-guess state), their respective errors and the laws of physics. The analysis can be used in a number of ways, including (i) providing initial conditions for a numerical weather forecast (initialization), (ii) studying climate through merging of observations and numerical models (reanalysis), (iii) assessing the impact of individual components of the existing observation network, (iv) predicting the potential impact of proposed new components of a future observation network.

Importance of accurate initial conditions to the success of an assimilation/forecast of a numerical weather prediction (NWP) system is well known [5,7]. This is not to belittle other important aspects such as physical parameterization schemes. However, better initial conditions are increasingly considered vital for a whole range of NWP applications for both operational and research purposes.

The three components of the 3DVAR system used to enforce the minimization of the 3DVAR cost-function are observations, a previous background forecast, and estimates of observation and background error [10]. In order to run a bounded forecast model from the analysis, lateral boundary conditions must be modified to take account of the differences between background and analysis fields.

\subsection{Variational Data Assimilation}

In recent years, serious efforts have been initiated towards the development of variational data assimilation systems to replace previously used schemes such as the Cressman, Newtonian nudging, optimum interpolation, and analysis correction algorithms [11]. The 3DVAR problem can be summarized as the iterative solution of the minimization of a prescribed cost-function [12], i.e. to find the analysis state $x$ that minimizes $J(x)$ in Eq. (1). This solution represents the posteriori maximum likelihood (minimum variance) estimate of the true state of the atmosphere given the two sources of a priori data: the background (previous forecast) $x^{b}$ and observations $y^{o}$ [13]:

$$
J(x)=J^{b}+J^{o}=\frac{1}{2}\left(x-x^{b}\right)^{T} B^{-1}\left(x-x^{b}\right)+\left(y-y^{o}\right)^{T} R^{-1}\left(y-y^{o}\right)
$$

where $x$ is a vector of analysis, and the other symbols have their usual meaning [4].

\subsection{Literature Survey on Assimilation of QuikSCAT Data}

Quick Scatterometer (QuikSCAT) data are available in near-real time in the National Oceanic and Atmospheric Administration/National Center for Environmental Prediction (NOAA/NCEP) Advanced Weather Interactive Processing System (N-AWIPS) and are used extensively in manual analyses of surface winds [14]. The high resolution QuikSCAT data is routinely utilized at the NOAA/NCEP Ocean Prediction Center (OPC), Tropical Prediction Center (TPC), and other NOAA weather forecast offices (WFOs) to improve the accuracies of wind warnings in marine forecasts for high-wind warnings. Scatterometer data are now routinely used by operational weather forecasters as most research and operational applications of satellite measurements of ocean winds require both wind speed and direction [15]. However, the information content of the QuikSCAT data was underutilized in the NWP models in the initial years [14].

The WindSat polarimetric radiometer (launched in January 2003) as a "risk reduction demonstration project" [16] is providing useful insight into the performance to determine the wind speed and directional accuracy of WindSat retrievals over a wide range of environmental conditions. However, analyses indicate that the errors of these WindSat wind estimates are about 30\% larger than the QuikSCAT measurement errors [17, 18]. Although the WindSat measurement accuracy is likely to improve with refinements of the retrieval algorithms, it may not match the accuracy of scatterometer wind retrievals.

Chen analyzed and compared the Spectral Sensor Microwave Imager (SSM/I), the QuikSCAT winds, and dropsonde winds for a hurricane using MM5 and its 3DVAR system [19]. Comparison of the wind direction observed by QuikSCAT with those from the dropsondes showed the good quality of QuikSCAT data. The increment of the QuikSCAT wind analysis was more marked than that from the SSM/I analysis due to the correction of the storm location - a positive result from the assimilation of wind vectors. The increase in low-level wind speeds enhanced the air-sea interaction processes and improved the simulated intensity for the hurricane while the storm structure was better simulated. Marked and clear improvement was noted in the simulation of the storm track particularly due to assimilation of QuikSCAT wind vectors; however, lack of information about the wind direction from SSM/I data resulted in less improved simulation. The sea level pressure (slp) and maximum low-level wind errors were considerably reduced as compared with the CTRL experiment. QuikSCAT data were superior to SSM/I-observed winds since the former also contained wind direction information. The position of the center of hurricane, cyclone, or frontal system position over the ocean may be misrepresented at the model initial time; 
hence good quality information on wind direction can potentially correct the initial location of the system, and impact the simulated system intensity and track. The agreement of the simulated storm position with the best track at the model initial time was primarily due to the assimilation of QuikSCAT wind vectors. However, these results are not adequate; additional number of case studies is necessary for providing broad and general conclusions.

Impact of assimilating satellite data [QuikSCAT near surface winds, SSM/I wind speed and Total Precipitable Water (TPW)] for forecasts of wind, temperature, and humidity from 1-month assimilation experiments during July 2006 by Rakesh et al. (2009) [9] demonstrated that on average, the satellite data improved the MM5/WRF initial conditions and errors in predicted meteorological fields were reduced. Assimilation of satellite data (QuikSCAT wind, SSM/I wind, SSM/I TPW, or SSM/I wind and TPW) improved the wind speed prediction and the largest improvement in magnitude was observed due to QuikSCAT assimilation. A positive impact in temperature and humidity prediction was observed due to SSM/I TPW assimilation whereas the assimilation of SSM/I wind speed resulted in a degradation of temperature and humidity prediction at lower levels. The assimilation of QuikSCAT wind significantly improved quantitative rainfall prediction skill of the MM5/WRF for first day forecast. This impact was likely due to improvement in the boundary layer processes (moisture flux and convergence fields) since QuikSCAT contains wind speed as well as wind direction.

Govindankutty et al. (2008) [20] investigated the impact of ingesting the Moderate Resolution Imaging Spectroradiometer (MODIS) temperature and humidity profiles in the prediction of a monsoon depression using the WRF model and its 3DVAR system. Their results indicated better simulated slp fields and better simulated structure of the spatial precipitation pattern for the 3DVAR experiments, closer to the TRMM observations. Quantitative analysis through various skill measures (like BIAS, false alarm ratio (FAR) and probability of detection (POD) for precipitation; root mean square error (RMSE) for temperatures, dew point temperatures and wind speeds; and spatial correlation (SCORR) and RMSE for slp fields) suggested positive impact and better performance in forecasts due to MODIS data assimilation in the 3DVAR experiment. However, it was noted by Govindankutty et al., 2008 [20] that improving the model resolution and assimilating the MODIS data over several analysis cycles had contributed to the positive impact on simulation.

Vinodkumar et al. (2007) [21] investigated the impact of a surface data assimilation technique (SDA) and fourdimensional data assimilation (FDDA) for simulating a monsoon depression that formed during the Bay of Bengal Monsoon Experiment (BOBMEX) 1999 field campaign. They conducted SDA experiment and FDDA experiment using the MM5 model where the NOAA's Television Infrared Observation Satellite (TIROS) Operational Vertical Sounder (TOVS) data, QuikSCAT data and conventional upper air and surface meteorological data were assimilated to provide an improved analysis. When compared with the analysis and the BOBMEX 1999 buoy, ship, and radiosonde observations, the simulated sea level pressure, simulated rainfall and the large-scale structure of the monsoon depression from SDA and FDDA run results showed resemblance with the analysis over the results obtained under their CONTROL run experiment with no data assimilation. The impact of FDDA and SDA (the latter restricted over land) resulted in reduced errors in simulated temperature, wind speed, wind direction, and relative humidity when compared with the BOBMEX buoy observation as compared to CONTROL run results. The CONTROL simulation indicated a very weak system with a higher central pressure as compared with model runs with data assimilation. The comparison of the model results with the BOBMEX 1999 observations indicated a better agreement of the simulations with FDDA and SDA compared with the CONTROL simulation.

Vinodkumar et al. (2008) [22] studied the impact of the Flux-Adjusting Surface Data Assimilation System (FASDAS) and the four-dimensional data assimilation (FDDA) using analysis nudging for simulating a monsoon depression formed during the 1999 Bay of Bengal Monsoon Experiment (BOBMEX) field campaign using the MM5 model. The FASDAS scheme involved the indirect assimilation of soil moisture and ground/skin temperature over land with the direct continuous assimilation of surface temperature and surface humidity which provided realistic surface latent and sensible heat flux simulations. The initial analysis for the FDDA and the surface data assimilation (SDA) runs was improved by ingesting the humidity and temperature profiles from the NOAA-TOVS, surface winds from the QuikSCAT, and the conventional meteorological upper-air (radiosonde/rawinsonde, pilot balloon) and surface data. They compared the results from three simulations with NCEP reanalysis, TRMM observations, and the special buoy, ship, and radiosonde observations available during the BOBMEX 1999. As compared with the Control (CTRL) run experiment results (where no data was assimilated), the FASDAS and the FDDA runs showed a relatively betterdeveloped cyclonic circulation and a larger spatial area as well as improved rainfall amounts. The FASDAS run showed a consistently improved model simulation performance in terms of RMSE of surface humidity and surface temperature as compared with the CTRL and the FDDA runs. Their results suggested that the FASDAS run's performance was best overall. The assimilation of the QuikSCAT wind data and surface-analyzed winds over the land improved the simulation of surface winds. Also, the results in comparison with the BOBMEX observations indicated reduced errors on all surface fields for the FASDAS run as compared to the CTRL and FDDA runs. The study demonstrated the benefits of ingesting and assimilating different satellite and conventional observations using FASDAS and FDDA.

Xavier et al. (2008) [3] used the MM5 model to study the effect of assimilated satellite and conventional data on the prediction of three monsoon depressions over India using analysis nudging. The satellite data included the vertical profiles of temperature and humidity (from NOAA-TOVS and MODIS) and the surface wind vector over the sea (from QuikSCAT). The conventional data were the upper-air and surface data from the India Meteorological Department (IMD). Two experiments - NOFDDA (no nudging) and FDDA (assimilating the satellite and conventional data for 
an improved analysis through analysis nudging) were performed for each case study. They compared the results from simulations with the analysis and observations. Their results showed that the predicted sea level pressure (slp), the lower tropospheric cyclonic circulation, and the precipitation of the FDDA simulation reproduced the large-scale structure of the depression as manifested in the NCEP reanalysis. The simulation of slp using no assimilation high-resolution runs with the Kain-Fritsch (KF) cumulus parameterization scheme appeared poor in comparison with the FDDA run, while the no assimilation high-resolution runs with the Grell cumulus scheme provided better results. However, the space correlation and the RMSE of slp obtained under KF scheme using no assimilation were better than those from FDDA run. Simulation of precipitation with the $3.3 \mathrm{~km}$ high-resolution under no assimilation run did not prove better than the precipitation simulation with the FDDA run. Hence, their study significantly showed that over the Indian monsoon region, the improvements in the simulation using nudging in the FDDA run were of similar magnitude (or better) than the improvements in the simulation due to high-resolution and to cumulus parameterization sensitivity. The improvements in the FDDA run due to analysis nudging were also verified in two more depression cases.

The response of an ocean general circulation model (OGCM) to two different wind forcings (NCEP reanalysis and QuikSCAT), was examined by Agrawal et al. (2007) [23]. NCEP wind forcing (NCEP-R) and QuikSCAT wind forcing (QS-R) were compared with one another and were also compared against observations for a period of 3 years (2000-2002). The sea-level anomaly (SLA) simulated by QS-R had less RMSE and higher correlation with respect to the Ocean Topography Experiment (TOPEX)/Poseidon SLA observations than the SLA simulated by NCEP-R. Intraseasonal variability of currents observed by the Triangular Trans Ocean Network (TRITON) buoy in the Indian Ocean was closely captured by QS-R, although the magnitudes were somewhat underestimated. QS-R simulated surface currents had less RMSE than those simulated by NCEP-R in the Pacific. However, the sub-surface currents were much weaker in magnitude in both solutions. A better BIAS was obtained for sea-surface temperature (SST) when simulated by QS-R. However, the RMSE of SST simulated by NCEP-R was less than the RMSE of SST simulated by QS-R though the latter captured the variabilities more realistically. QS-R simulations of $20^{\circ} \mathrm{C}$ thermocline depths (D20) were also in better agreement with in situ derived D20 than the D20 simulated by NCEP-R. In addition, variations in the mixed layer depth at the TRITON buoy were better captured by QS-R than by NCEP-R. Speed of Kelvin and Rossby waves and the strength of upwelling/downwelling features in the Indian Ocean were found closer to observations in QS-R than in NCEP-R simulations.

The objective of the study is to investigate the impact of assimilating surface wind observations over the sea from QuikSCAT in the WRF model using a 3DVAR assimilation technique in simulating meteorological systems (two monsoon depressions) over the Indian region. Section 2 provides a brief description of the model options used and the methodology employed, and section 3 gives the synoptic conditions which prevailed during the formation of the two depressions, being investigated in this study. Section 4 provides for the results and discussions while the final section outlines the broad conclusions of this study.

\section{MODEL OPTIONS AND METHODOLOGY}

For the present study, the WRF model was configured with twenty-eight vertical layers and run on a single domain of $30 \mathrm{~km}$ horizontal grid spacing with $130 \times 118$ grid cells in the east-west and north-south directions. The model was set with the Yonsei University scheme for planetary boundary layer, the Kain-Fritsch scheme for cumulus parameterization, the WRF Single-Moment 3-class scheme for microphysics (ice and snow processes), the RRTM scheme for longwave radiation, Dudhia scheme for shortwave radiation, 5-layer thermal diffusion for land surface (soil temperature only) and Monin-Obukhov similarity formulation for the surface layer.

The NCEP GFS (global forecast) data fields available at a horizontal grid spacing of $1^{\circ} \times 1^{\circ}$ and a time resolution of 03 hours were used for the initial and lateral boundary conditions. Two model runs were employed in this study first a control or a base run without any data assimilation and another a 3DVAR run in which QuikSCAT observations were assimilated using the 3DVAR assimilation. The control (CTRL) model integrations were performed from 00 UTC of the start date for the desired number of hours (usually 48 hours or 60 hours) without any assimilation. In the 3DVAR run, 3DVAR assimilation of observation data was performed at 00 UTC of the start date and in two 12 hourly successive cycles. Subsequently, for the 3DVAR run, the model was integrated in the free-forecast mode for desired number of hours without further assimilation. The model results from both runs were compared with one another as well as with the Tropical Rainfall Measurement Mission (TRMM) observations and GFS analysis for the duration when no observations were assimilated.

The model domain containing the Indian subcontinent is shown in Fig. (1). Fig. (1) also shows the terrain heights used in this study. Locations of the Head Bay is approximately covered by a unfilled rectangular area (Digha $21.8^{\circ} \mathrm{N} 87.8^{\circ} \mathrm{E}$ is one of locations near eastern coasts of India) and locations of the Orissa coasts (like Chandipur $21.5^{\circ} \mathrm{N} 86.9^{\circ} \mathrm{E}$, Paradip $20.3^{\circ} \mathrm{N} 86.7^{\circ} \mathrm{E}$, Puri $19.5^{\circ} \mathrm{N} 85.5^{\circ} \mathrm{E}$ and Gopalpur $19.2^{\circ} \mathrm{N}$ $84.6^{\circ} \mathrm{E}$ ) are shown by filled circles which are connected with a solid line to mark the Orissa coastline in Fig. (1). The center of the MD, formed on 28 September 200600 UTC and located at $18.0^{\circ} \mathrm{N} 89.0^{\circ} \mathrm{E}$, is shown by a filled square in Fig. (1) while the inner core of $3^{\circ} \times 3^{\circ}$ area of the MD is depicted as an unfilled square which has boundaries separated by $1.5^{\circ}$ away from the central location of the MD. The $3^{\circ} \times 3^{\circ}$ area, as defined here, represents the typical inner core of MD at each time which will have different locations at different times.

\section{SYNOPTIC CONDITIONS}

The synoptic conditions which prevailed over India during the formation of the two monsoon depressions that formed over the Bay of Bengal (and are investigated in this study) are given below.

A low pressure system formed over the Head Bay near the Orissa coast $\left(20.0^{\circ} \mathrm{N}, 87.5^{\circ} \mathrm{E}\right)$ by late hours of 02 


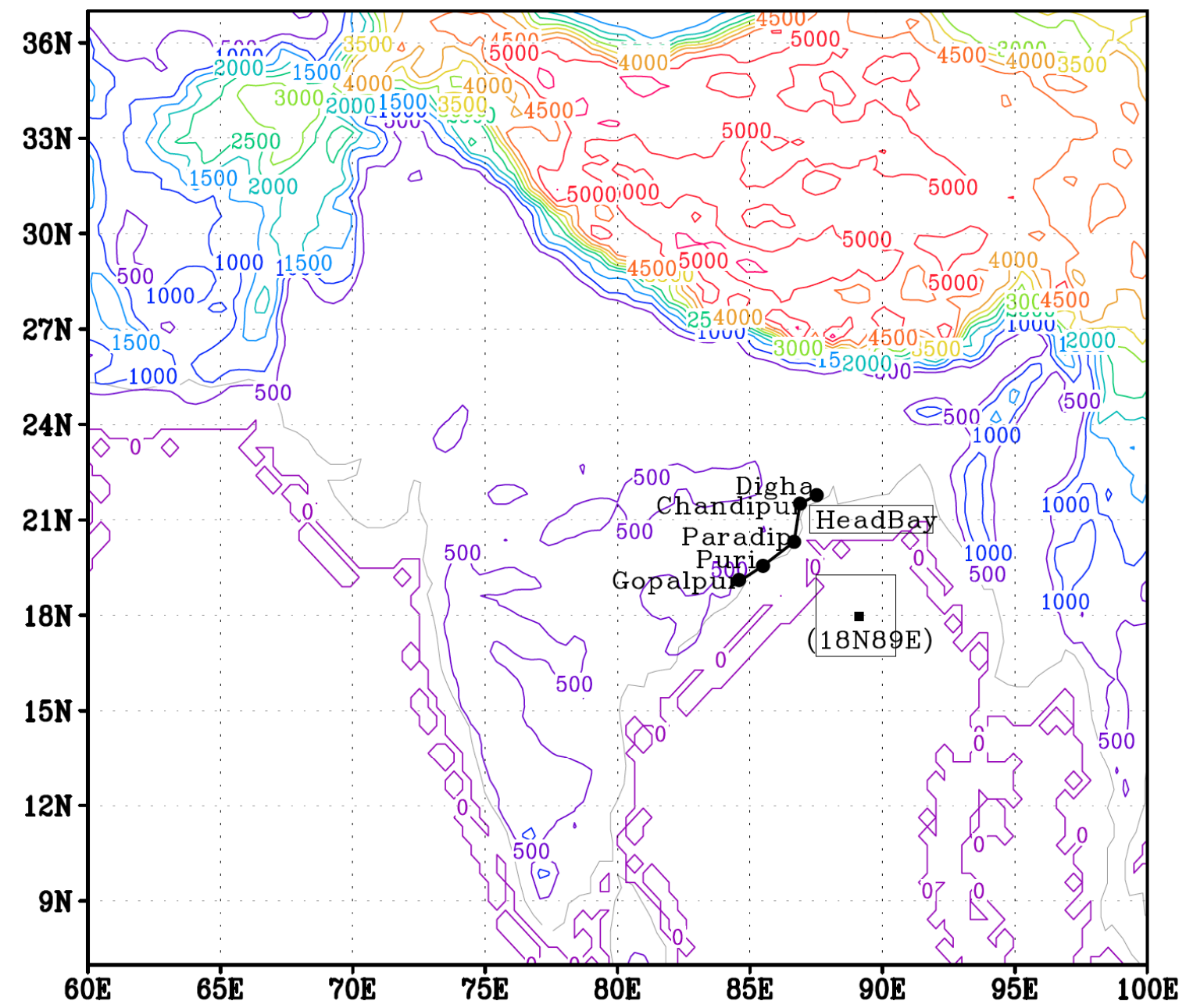

Fig. (1). Model domain used for the simulation of the two monsoon depressions and model terrain heights as used in this study. The rectangular area shows Head Bay region. Filled circles (connected with a solid line) show locations of the Orissa coastline. The $3^{\circ} \mathrm{x} 3^{\circ}$ area of the MD (formed on 28 September $200600 \mathrm{UTC}$, located at $18.0^{\circ} \mathrm{N} 89^{\circ} \mathrm{E}$ ) is demarcated by an unfilled square.

September 2006 which subsequently developed into a depression at 00 UTC 03 September 2006. The east coast and central plains of India recorded a maximum 24 hours rainfall of $35 \mathrm{~cm}$, centered over the Head Bay, near the Orissa coast, observed at 00 UTC 04 September 2006. However, the maximum 24 hours rainfall recorded for the next day was only $16 \mathrm{~cm}$ over the central plains of India. The depression started dissipating in the late hours of $4^{\text {th }}$ September and by early hours of $5^{\text {th }}$ September 2006 . The wind speed observed during the development of monsoon depression was between $10-15 \mathrm{~ms}^{-1}$ and the wind direction was mainly southwesterly over the Bay of Bengal and curved cyclonically in the vicinity of the monsoon depression.

Fig. (2a-d) show the observed QuikSCAT surface wind speeds over the sea at 00 UTC of 2-5 September, 2006. Fig. (2) shows that the maximum surface wind speeds are over the northern Arabian Sea and central Bay of Bengal while typically weak winds are seen over southern Arabian Sea on all the four days.

The monsoon depression of 27-30 September 2006 formed initially as a low pressure system over east-central and north eastern parts of the Bay of Bengal in the late hours of $27^{\text {th }}$ September 2006 . This low pressure system intensified into a depression in the early hours of $28^{\text {th }}$ September 2006 and lay centered near $18.0^{\circ} \mathrm{N} 89.0^{\circ} \mathrm{E}$. On $29^{\text {th }}$ September 2006, the depression moved to the eastern coasts of India near the Orissa coast and was centered near $19.0^{\circ} \mathrm{N} 86.0^{\circ} \mathrm{E}$ in the early hours while the depression was found near $19.0^{\circ} \mathrm{N}$ $84.5^{\circ} \mathrm{E}$ in the late afternoon hours. Heavy rainfall of about 24 $\mathrm{cm}$ was reported in the Bay of Bengal region and over the Orissa coasts on both days.

Fig. (3a-d) show the observed QuikSCAT surface wind speeds over the sea at 00 UTC of 28-30 September, 2006 respectively. For the first day (27 September 2006), Fig. (3a) shows that the maximum surface wind speeds are over the eastern and central Bay of Bengal, i.e., east of $85^{\circ} \mathrm{E}$ while typically weaker winds are seen over the Arabian Sea during the next three days.

\section{RESULTS AND DISCUSSION}

\subsection{Case Study 02-05 September 2006}

The 3DVAR assimilation of the QuikSCAT (Quick Scatterometer) surface wind data was performed in the 

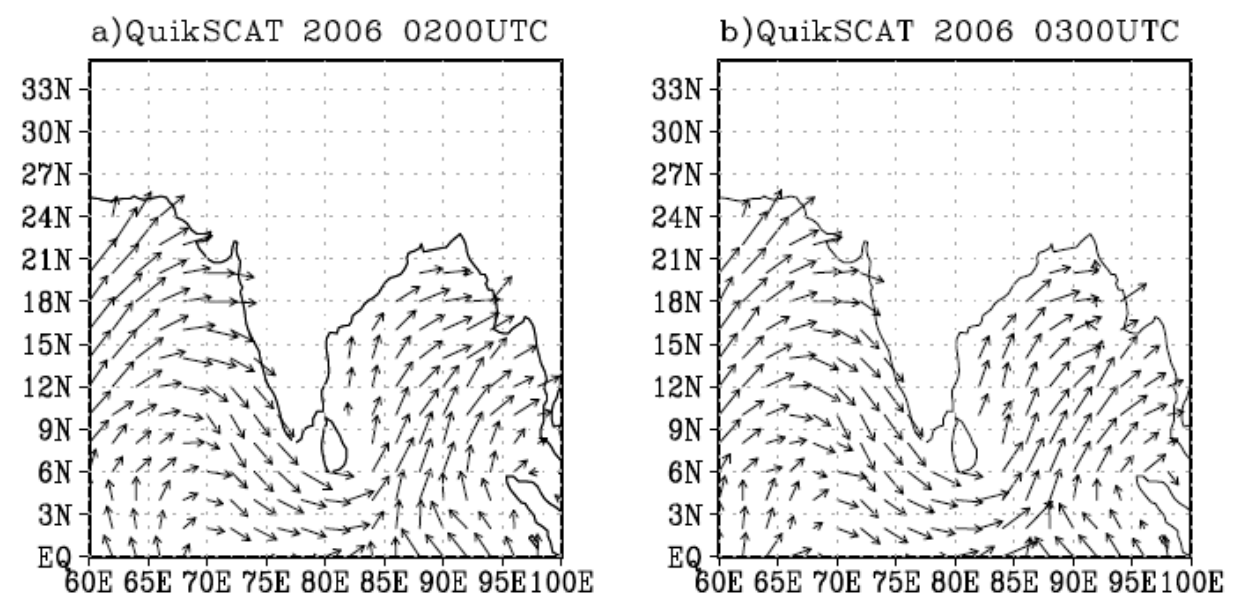

c)QuikSCAT 2006 0400UTC

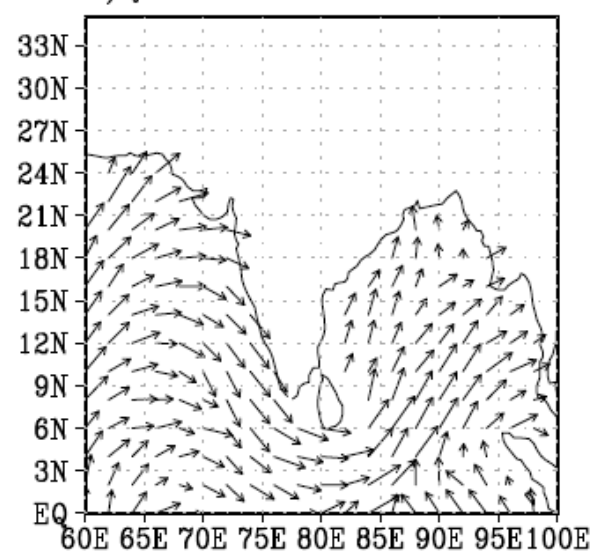

d)QuikSCAT 2006 0500UTC

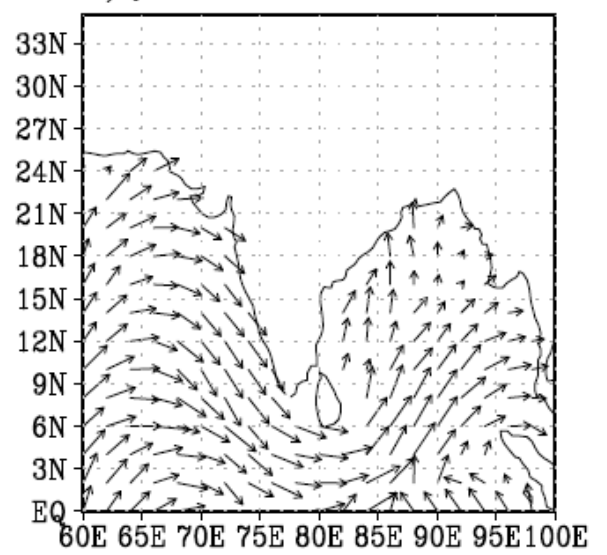

20

Fig. (2). QuikSCAT near surface wind observed at $00 \mathrm{UTC}$ of $2^{\text {nd }}(\mathbf{a}), 3^{\text {rd }}(\mathbf{b}), 4^{\text {th }}$ (c) and $5^{\text {th }}$ (d) September 2006.

simulation of the 2-5 September 2006 monsoon depression using the WRF-ARW modeling system. The CTRL run was integrated from 02 September 200600 UTC to 05 September 200600 UTC without any assimilation of observations. For the 3DVAR run, QuikSCAT surface wind data was assimilated from 02 September 200600 UTC to 03 September 200600 UTC with a 12 hourly cycle, and the model was then subsequently integrated in a free forecast mode from 03 September 200600 UTC to 05 September 200600 UTC without any additional assimilation of QuikSCAT data.

Fig. (4a-o) depict the mean sea level pressure (mslp) and the wind vector at $950 \mathrm{hPa}$ from the NCEP-GFS analysis (Fig. 4a-e) and the CTRL (Fig. 4f-j) and the 3DVAR (Fig. 4k-o) runs, respectively for the 2-5 September 2006 depression. The above figures show that the CTRL run experiment has produced an intense depression with enhanced cyclonic circulation on 04 September 2006 which continues to intensify to late hours of the day while the 3DVAR results reveal improved patterns of mean sea level pressure which are in good agreement with GFS-ANL fields.
The center of the monsoon depression is reasonably well depicted for the first day in the 3DVAR simulation while the depression dissipates during the late hours of the second day of the forecast in the 3DVAR run.

Fig. (5) displays the GFS-ANL, and the two model output profiles of the difference of the time averaged and area averaged temperature over the depression area (of size $3^{\circ} \times 3^{\circ}$ ) and the environment (entire domain area) in Kelvin for the 2-5 September 2006 depression. The temperature difference profile shown in Fig. (5) is time averaged over two days using every 6 hourly model output. The $3^{\circ} \times 3^{\circ}$ area of the MD defined above in section 2 is used to obtain the area averaged profile of temperature difference over the depression area and the environment as well as the area averaged profile of relative vorticity over the depression area.

A "well-defined" cold core structure for the monsoon depression indicates that the temperature values over the depression area are less compared to the environment. Typically, the thermal structure of a monsoon depression has 
a)QuikSCAT 2006 2700UTC

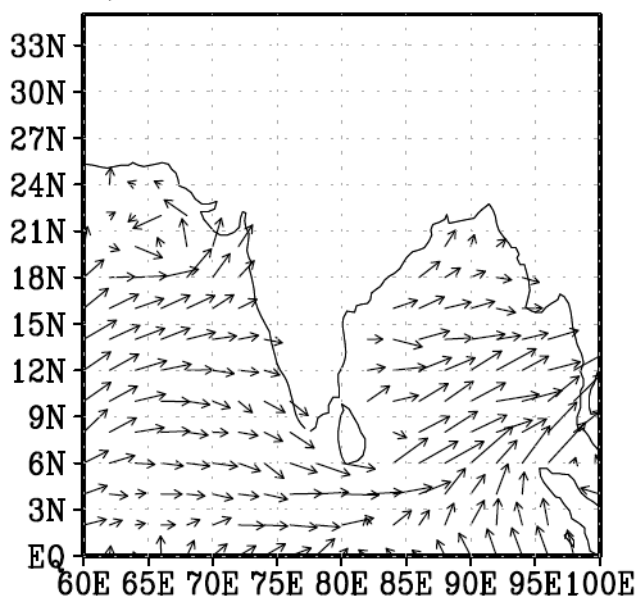

b)QuikSCAT 2006 2800UTC

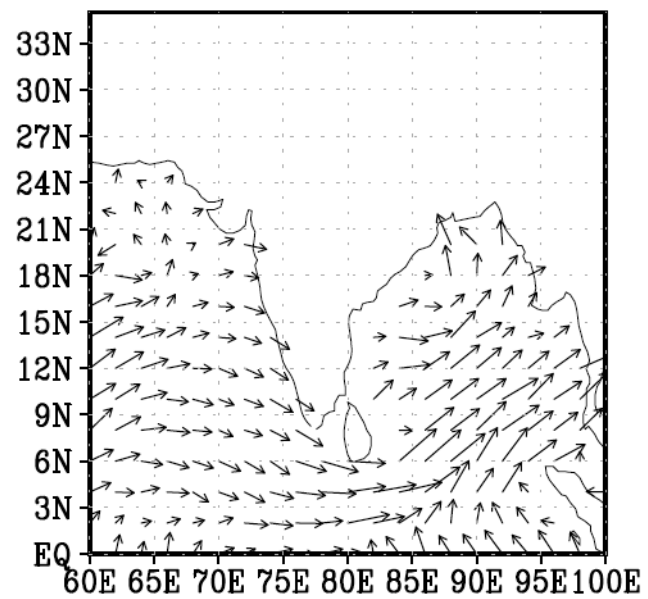

c)QuikSCAT 2006 2900UTC

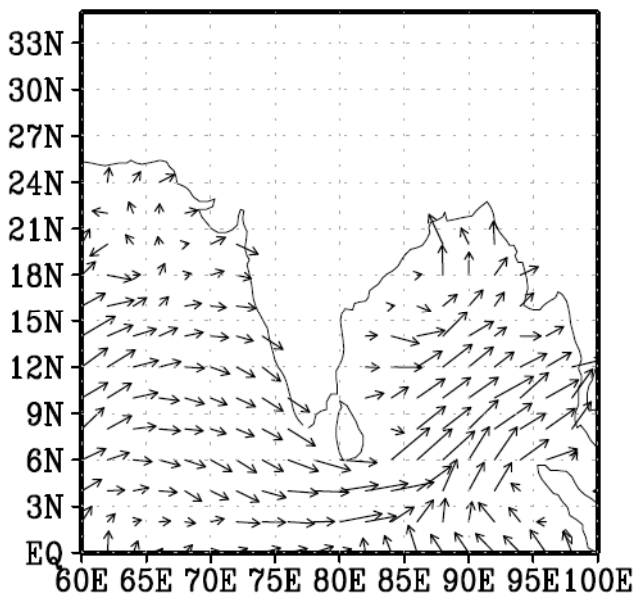

d)QuikSCAT 2006 3000UTC

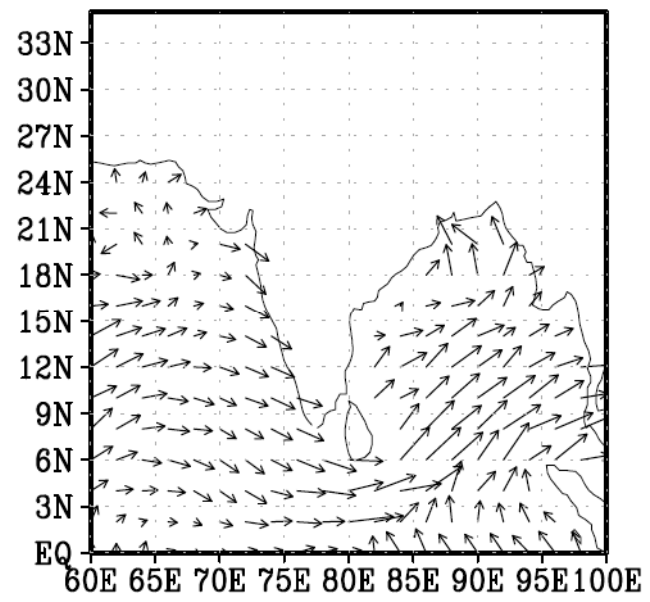

Fig. (3). QuikSCAT near surface wind observed at 00 UTC of $27^{\text {th }}\left(\right.$ a) $, 28^{\text {th }}(\mathbf{b}), 29^{\text {th }}$ (c) and $30^{\text {th }}$ (d) September 2006.

cold-core structure in the lower troposphere and warm-core structure at mid-tropospheric layers. Difference in temperature over the depression area and the environment of GFS-ANL shows negative values at lower levels (900-700 $\mathrm{hPa}$ ) which indicate presence of cold core in the lower troposphere and positive values at higher levels (600-400 $\mathrm{hPa}$ ) which indicate presence of warm core in the midtroposphere (Fig. 5) for the monsoon depression. While both model results do not simulate the marked cold core structure unlike seen in the lower troposphere in the GFS-ANL, the 3DVAR run does simulate a rather deep cold core region extending from $900 \mathrm{hPa}$ to $600 \mathrm{hPa}$. However, the height of the maximum difference of the cold core is not well simulated by the 3DVAR run. The simulation of the cold core structure in the CTRL run is rather shallow $(950-850$ $\mathrm{hPa}$ ) and has a lower magnitude as compared to the 3DVAR run.
Furthermore, the air temperature difference in the midtroposphere for the 3DVAR results shows very good agreement with the GFS-ANL results. Although the CTRL model results also exhibit presence of cold core in the lower troposphere and warm core in the mid-troposphere, there is less agreement of the CTRL run results with GFS-ANL.

Fig. (6) shows a similar profile of the time averaged and area averaged relative vorticity over the depression area (of size $3^{\circ} \times 3^{\circ}$ ) for the GFS-ANL, and the two model outputs. The time averaged and area averaged relative vorticity profile from the 3DVAR model run shows a maximum cyclonic vorticity close to $950 \mathrm{hPa}$ and an anticyclonic vorticity above $250 \mathrm{hPa}$ and are in good agreement with GFS-ANL. However, while the CTRL run also shows similar trend, the magnitude of the time averaged and area averaged relative vorticity values are very much higher at 
a) GFS-ANL 0300UTC

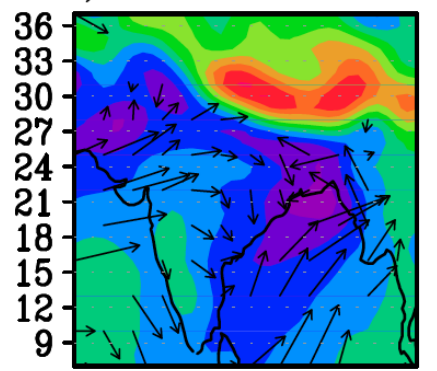

b)GFS-ANL 0312UTC

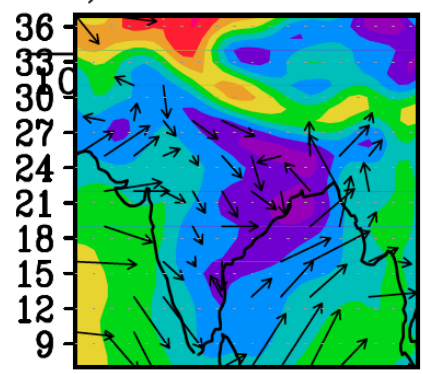

c) GFS-ANL 0400UTC

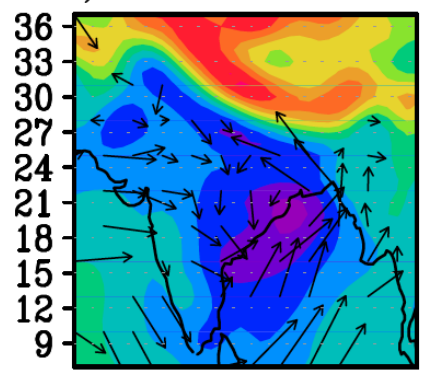

d)GFS-ANL 0412UTC

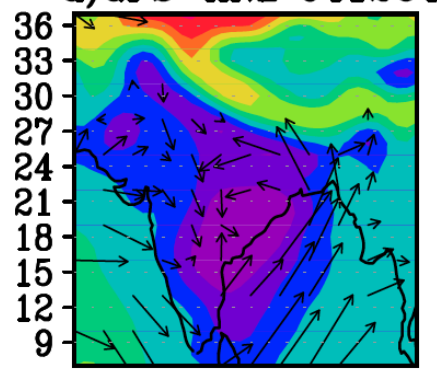

e)GFS-ANL 0500UTC

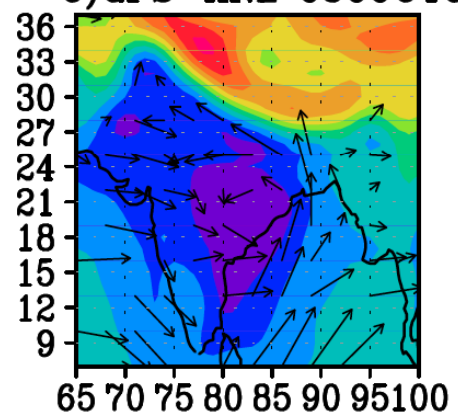

f)CTRL 0300UTC

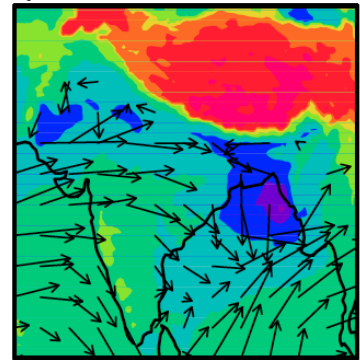

g)CTRL 0312UTC

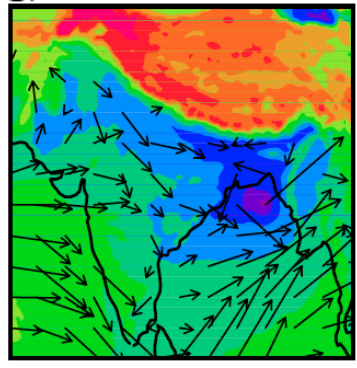

h)CTRL 0400UTC

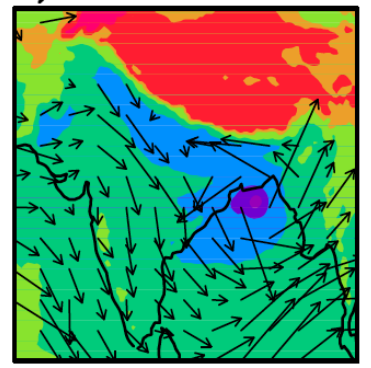

i)CTRL 0412UTC

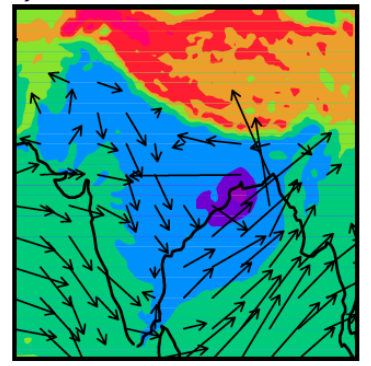

j)CTRL 0500UTC

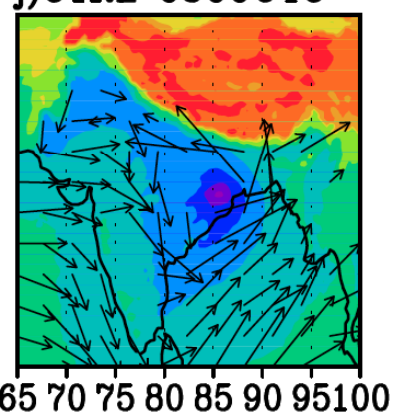

k)3DVAR 0300UTC

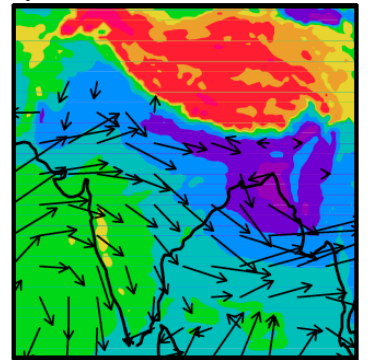

\section{1)3DVAR 0312UTC}

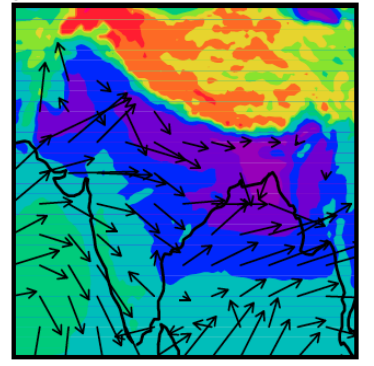

m)3DVAR 0400UTC

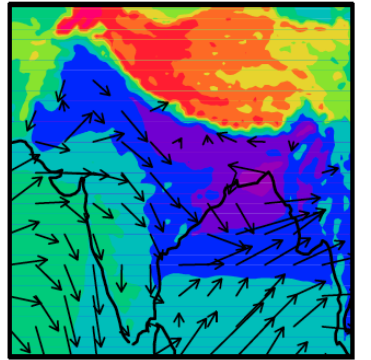

n)3DVAR 0412UTC

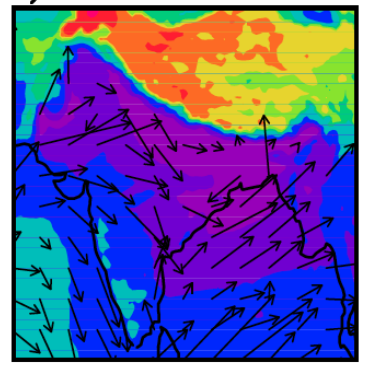

o)3DVAR 0500UTC

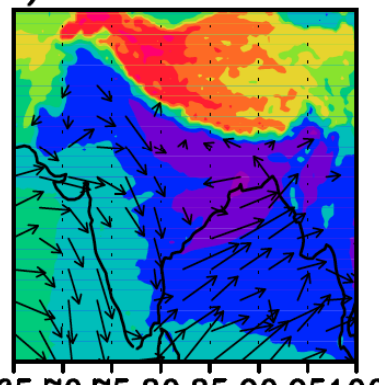

65707580859095100

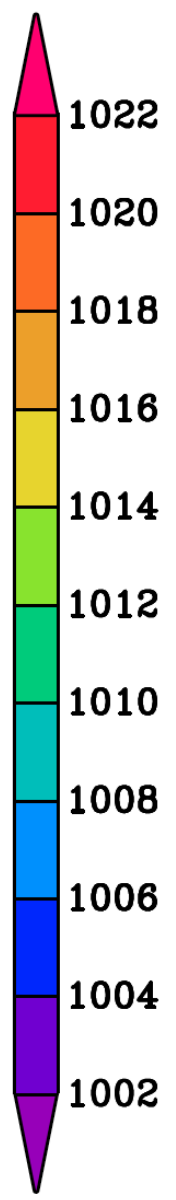

Fig. (4). Mean sea level pressure (hPa) \& wind vector $\left(\mathrm{ms}^{-1}\right)$ at $950 \mathrm{hPa}$ level from NCEP-GFS (a-e), CTRL (f-j) and 3DVAR (k-o) for monsoon depression of 02-05 September 2006.

almost all pressure levels as compared to the 3DVAR and GFS-ANL.
Fig. (7a-f) shows the 24-hour accumulated rainfall (reproduced at 04 and 05 September 200600 UTC) obtained 


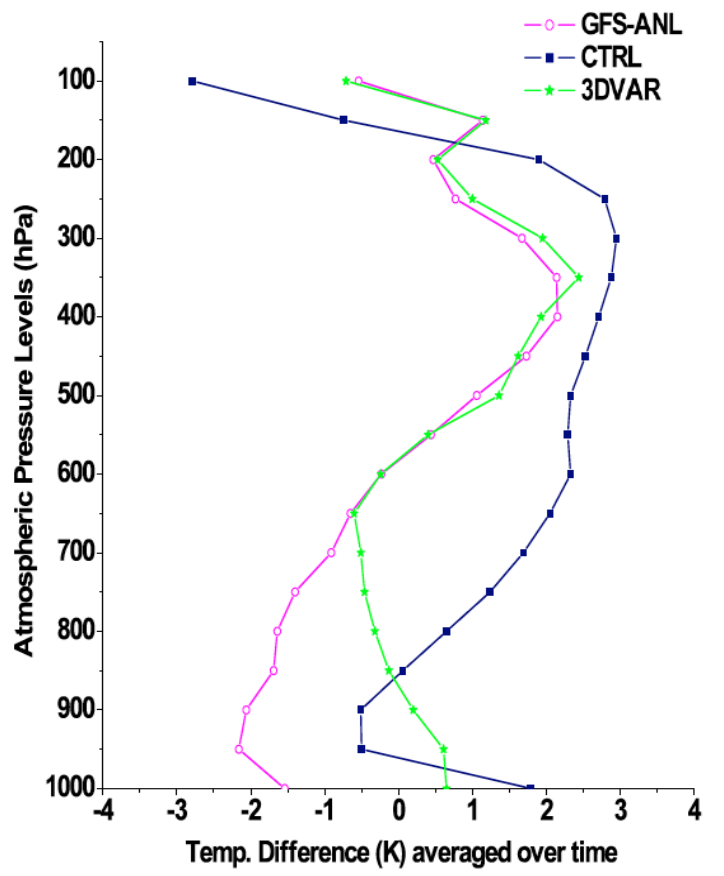

Fig. (5). Difference of Air Temperature over the depression area and the entire domain area, averaged over time, at various pressure levels in K for MD of 02-05 September 2006.

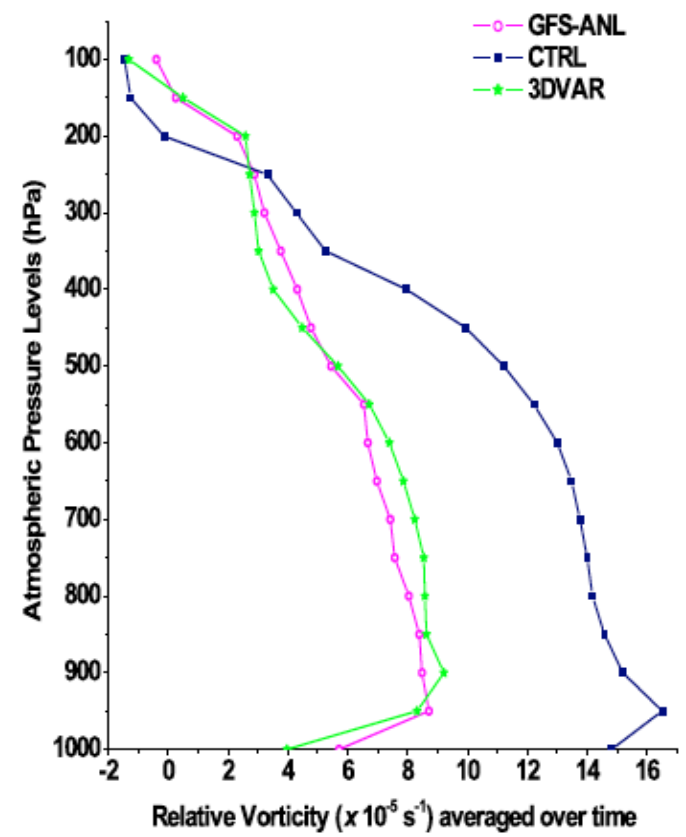

Fig. (6). Relative Vorticity (area averaged over the depression area) at various pressure levels, and averaged over time, for MD of 02-05 September 2006.

from TRMM (Fig. 7a, b) and from the WRF CTRL (Fig. 7c, d) and the 3DVAR (Fig. 7e, f) simulations. TRMM observations show intense rain over the Bay of Bengal close to the east coast of India with moderate rain over the east coast of India (Fig. 7a).

For the first day, both the CTRL and the 3DVAR runs correctly simulate the intensity of precipitation (Fig. 7c, e). However, both model runs do exhibit location errors of the maximum simulated precipitation on day one of the forecast.
Furthermore, both models do not simulate rain over land on day one of the forecast. The observed TRMM rain on the second day indicates that the depression has crossed land and has produced extensive rainfall over the central plains of India. Both model results, however, have simulated the rainfall over the Bay of Bengal with very little rainfall over the central plains of India.

In order to have quantitative measure of the effects of 3DVAR assimilation of QuickSCAT surface wind data, several quantitative scores (BIAS, false alarm ratio FAR, probability of detection POD, equitable threat score ETS), for the two simulations with respect to TRMM are calculated over the entire domain using the 48 hour accumulated precipitation and are shown in Figs. (8-11), respectively.

The equitable threat score is defined [24] as $\frac{(\mathrm{H}-\mathrm{CH})}{\mathrm{F}+\mathrm{O}-\mathrm{H}-\mathrm{CH}}$ where $\mathrm{F}=$ the number of grid boxes that forecast more than the threshold, $\mathrm{O}=$ the number of grid boxes that observe more than the threshold, $\mathrm{H}=$ the number of grid boxes that correctly forecast more than the threshold, $\mathrm{CH}=$ the expected number of correct forecasts due to chance $=\mathrm{F}^{*} \mathrm{O} / \mathrm{T}$ where $\mathrm{T}=$ the total number of grid boxes inside the verification domain.

ETS is basically the ratio of the correct forecast area to the total area of the forecast and observed precipitation which can vary from a small negative number to 1.0 , where 1.0 represents a perfect forecast. The model gets penalized for forecasting rain in the wrong place as well as not forecasting rain in the right place. Thus, the model with the highest score is generally the model with the best forecast skill. ETS is a good estimate for forecast skill - the higher the value, the better the forecast skill is for that threshold.

The BIAS score is defined [24] as F/O. This score gives an indication whether a model is consistently over- or underforecasting areas of precipitation. The best model is generally the one that remains near the 1.0 value, which means that the model does not generally over-forecast precipitation or under-forecast precipitation and indicates that the model forecast values of precipitation have the same frequency (or area coverage) as that of the observation. If BIAS is over 1.0, it is over-predicting precipitation, and if it is below 1.0 it is under-predicting precipitation.

As can be seen from Fig. (8), the BIAS rainfall values for the 3DVAR run are lower (between 1.0-1.5) than the CTRL run (above 2.0) for all rainfall thresholds. The lower BIAS values indicate that the $3 \mathrm{DVAR}$ run is less overestimating the precipitation as compared to the CTRL run (Fig. 8). Both model runs show a slight decrease in the BIAS values with the increase in the threshold rainfall indicating that both model runs exhibit lower overestimation with the high intense rainfall events.

For any threshold rainfall value, the forecast is either a yes or no statement (categorical forecast). The observation itself is put in one of two categories - event observed and not observed. Here, $\mathrm{H}$ denotes hits - the event is predicted to occur and it occurs, F signifies false alarms (event predicted but does not occur), $\mathrm{M}$ indicates missed forecasts (observed events not predicted) and $\mathrm{Z}$ denotes events not predicted 


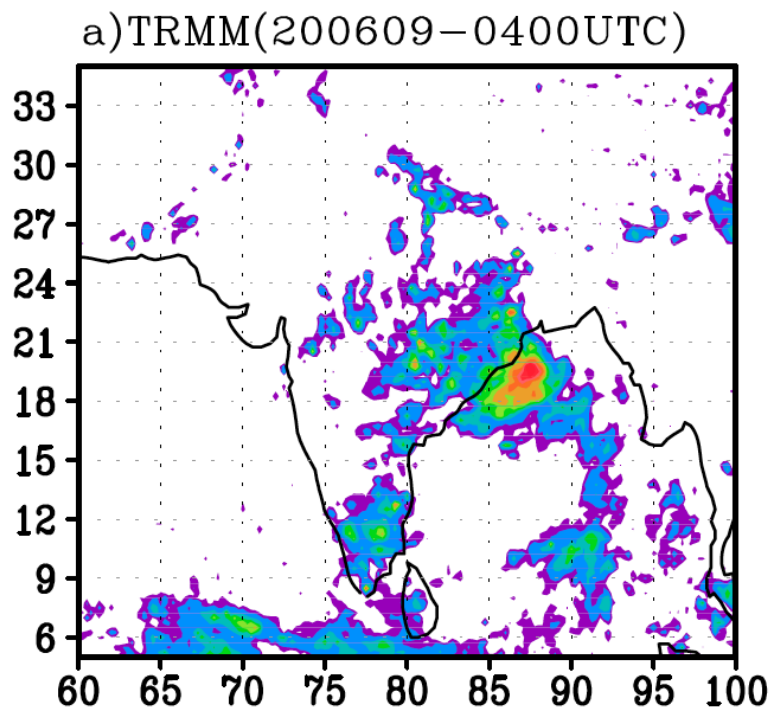

b) TRMM(200609-0500UTC)
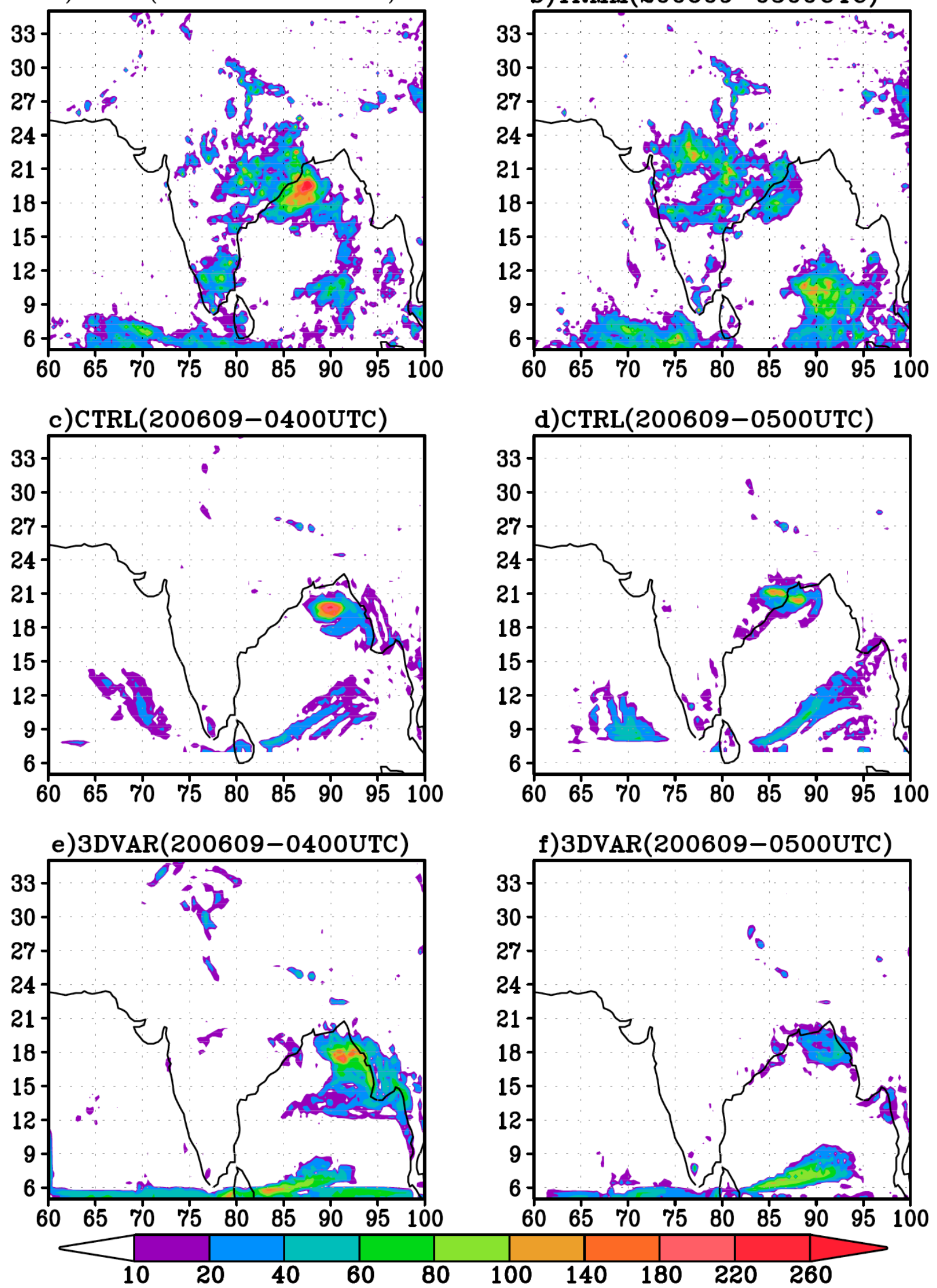

Fig. (7). $24 \mathrm{hrs}$ accumulated precipitation (mm) patterns for the first two days of forecast from TRMM (a, b), CTRL (c, d) and 3DVAR (e, f) for monsoon depression of 02-05 September 2006. 
which also did not occur. Let $\mathrm{N}$ be, $\mathrm{N}=\mathrm{H}+\mathrm{F}+\mathrm{M}+\mathrm{Z}$. A perfect forecast sample is when $\mathrm{F}$ and $\mathrm{M}$ are zero. A large number of verification scores are computed from these four values [25] (Table 1).

Table 1. A Forecast/Verification Table

\begin{tabular}{|c|c|c|}
\hline ForecastlObservation & Observed & Not observed \\
\hline \hline forecast & $\mathrm{H}$ & $\mathrm{F}$ \\
\hline not forecast & $\mathrm{M}$ & $\mathrm{Z}$ \\
\hline
\end{tabular}

The false alarm ratio $\mathrm{FAR}=\mathrm{F} /(\mathrm{H}+\mathrm{F})$, gives the fraction of forecast events that were observed to be non events. FAR gives a measure of the false alarms (model simulating rainfall where none exists). The probability of detection $\mathrm{POD}=\mathrm{H} /(\mathrm{H}+\mathrm{M})$, also known as Hit Rate $(\mathrm{HR})$, measures the fraction of observed events that were correctly forecast.

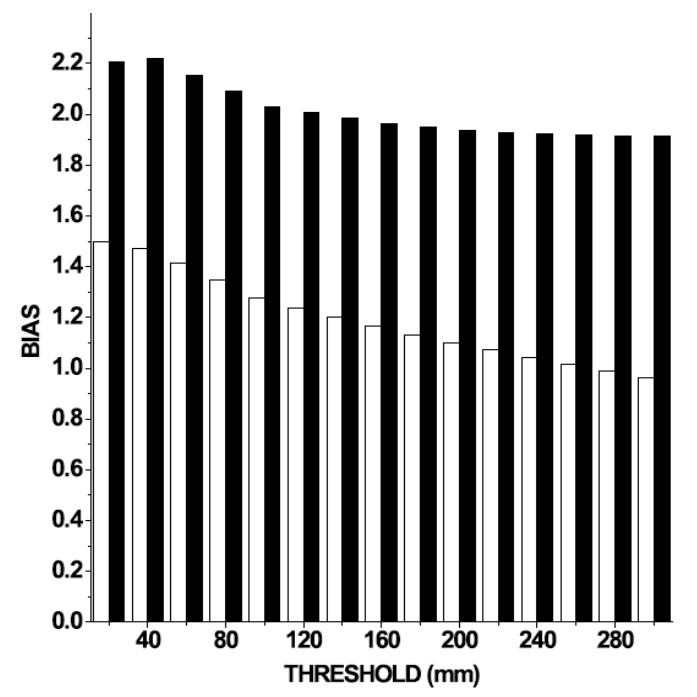

Fig. (8). BIAS for CTRL (filled bars) and 3DVAR (unfilled bars) simulations of MD of 02-05 Sept. 2006 for different rainfall thresholds.

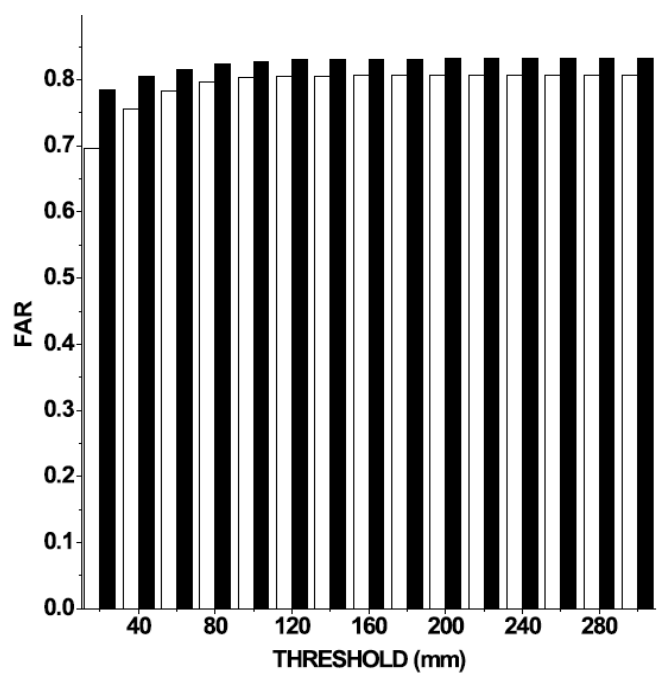

Fig. (9). FAR for CTRL (filled bars) and 3DVAR (unfilled bars) simulations of MD of 02-05 Sept. 2006 for different rainfall thresholds.
From Fig. (9), it is clear that the FAR for the CTRL run is higher as compared to the 3DVAR run for all rainfall threshold values. Fig. (9) also indicates that the FAR shows a slight increase with the rainfall thresholds for both model runs.

Fig. (10) shows the POD for both runs, indicating a clear and consistent increase of POD for the 3DVAR run as compared to the CTRL run for all rainfall thresholds, indicating that the 3DVAR run better simulates precipitation as compared to the CTRL run. The lower bias values and the lower false alarms of the 3DVAR run do ensure higher POD values for the $3 \mathrm{DVAR}$ run as compared to the CTRL run. Also, the values of POD for both runs show a decreasing trend with the increase of thresholds, indicating difficulties in simulating accurately the very heavy rainfall events for both model runs.

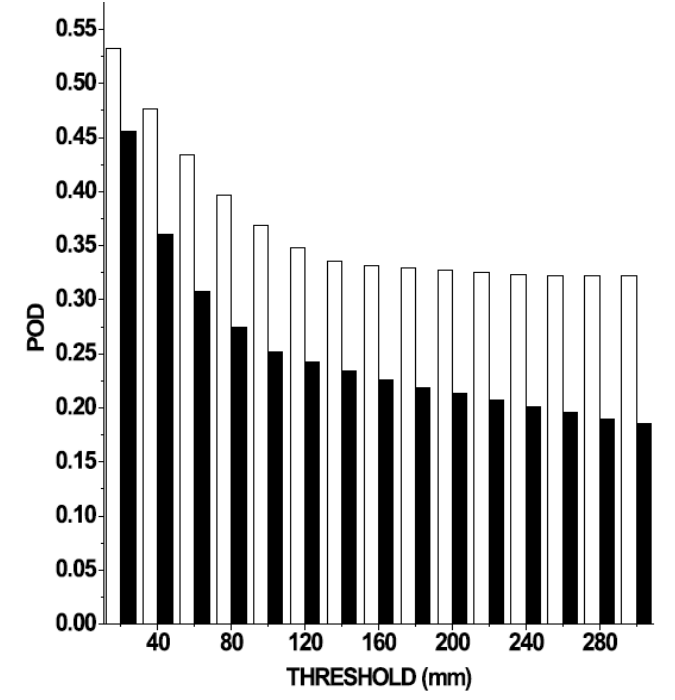

Fig. (10). POD for CTRL (filled bars) and 3DVAR (unfilled bars) simulations of MD of 02-05 Sept. 2006 for different rainfall thresholds.

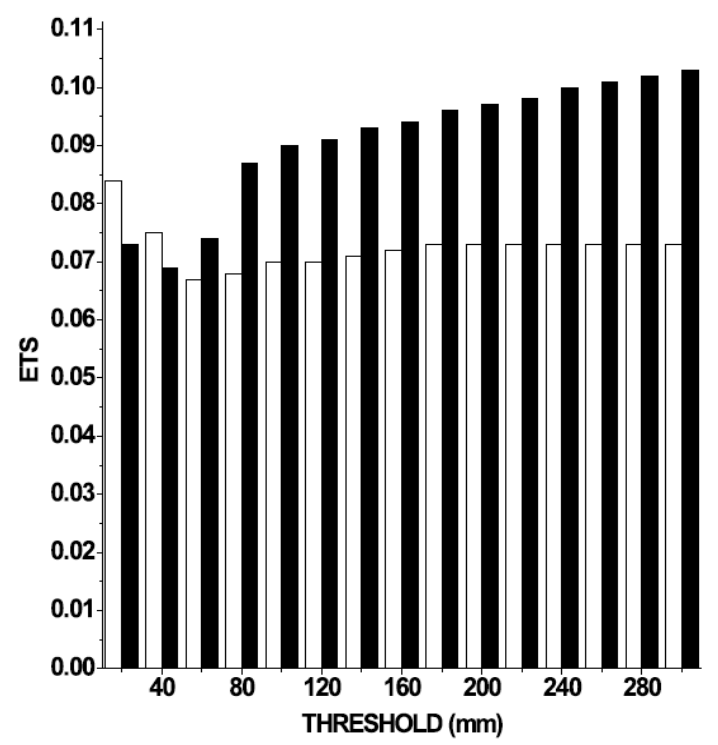

Fig. (11). ETS for CTRL (filled bars) and 3DVAR (unfilled bars) simulations of MD of 02-05 Sept. 2006 for different rainfall thresholds. 
Fig. (11) shows the ETS for both runs at different threshold rainfalls. ETS does take into account the hits that occur due to pure chance and provides a correct estimate of the skill score as far as the simulated precipitation is concerned. While the ETS for the 3DVAR run shows slightly higher values as compared to the CTRL run for low rainfall (less than or equal to $40 \mathrm{~mm}$ of rainfall), the opposite is true for the high and very high rainfall amounts. The above result appears surprising considering the lower overestimation, lower false alarms and higher POD of the 3DVAR run for all rainfall thresholds. However, the actual magnitude of the ETS values (between 0.07 and 0.1 ) clearly indicate that the magnitudes of both runs are quite low and the higher ETS for the CTRL run is not of much significance considering the low magnitudes of the ETS values for both runs.

The Root Mean Square Error (RMSE) is most frequently used for validation of the results of the atmospheric model $\left(\mathrm{x}_{\mathrm{fi}}\right)$ with observations $\left(\mathrm{x}_{\mathrm{oi}}\right)$ and is defined as the square root of the mean squared error and is given by [25].

The spatial correlation (SCORR) for mean sea level pressure (mslp) and the RMSE for area-averaged wind $\left(75^{\circ}\right.$ $\left.\mathrm{E}-95^{\circ} \mathrm{E}, 10^{\circ} \mathrm{N}-30^{\circ} \mathrm{N}\right)$ at $950 \mathrm{hPa}$ for the CTRL and 3DVAR simulations of monsoon depression of 02-05 September 2006 are calculated with respect to the GFS analysis and are shown in Figs. $(\mathbf{1 2}, \mathbf{1 3})$, respectively. The SCORR values are marginally higher for the 3DVAR run on the first day of the forecast as compared to the CTRL run while for the day two of the forecast, the improvement seen in the 3DVAR run on the first day is not seen (Fig. 12). The RMSE for the area averaged wind at $950 \mathrm{hPa}$ (Fig. 13) shows lower values for the $3 \mathrm{DVAR}$ run as compared to the CTRL run for almost all times except 00 UTC of 04 September 2006. Furthermore, there is a marked decrease in the RMSE of the area averaged winds at $950 \mathrm{hPa}$ with time and this is better manifested in the 3 DVAR run except at 00 UTC 04 September where RMSE is slightly higher for $3 \mathrm{DVAR}$ run results compared to that of CTRL run results.

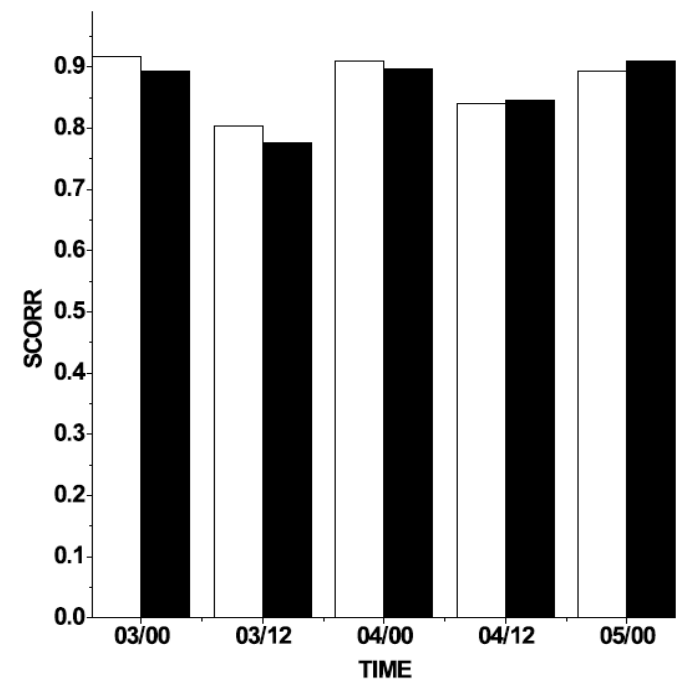

Fig. (12). SCORR for mslp for CTRL (filled bars) and 3DVAR (unfilled bars) simulations of MD of 02-05 Sept. 2006.

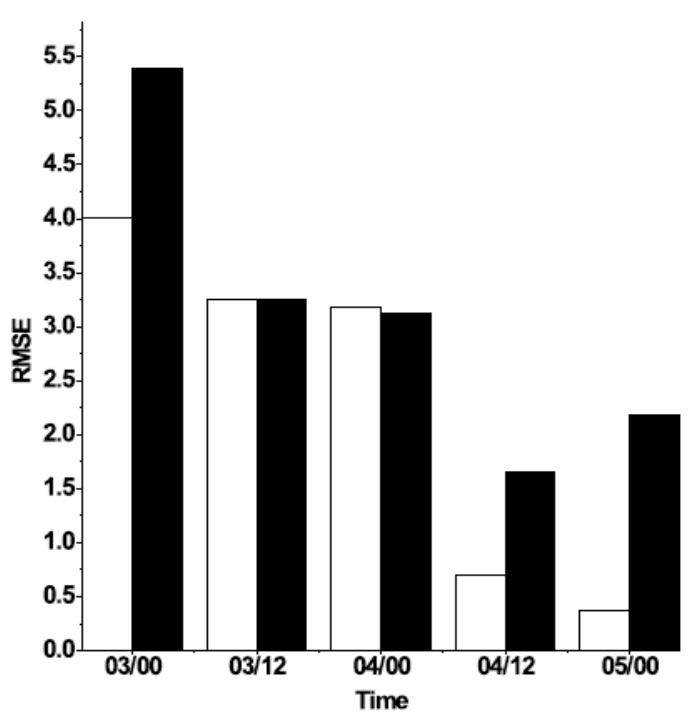

Fig. (13). RMSE in $\mathrm{m} \mathrm{s}^{-1}$ for area-averaged wind at $950 \mathrm{hPa}$ for CTRL (filled bars) and 3DVAR (unfilled bars) simulations of MD of 02-05 Sept. 2006.

The overall results of the study for the 2-5 September 2006 depression indicate that the assimilation of QuikSCAT wind data, on an average, has provided better simulations as far as improvements in the simulation of mean sea level pressure, wind vectors as well as the time and area averaged relative vorticity and the temperature difference profiles are concerned although this is not fully reflected in the spatial distribution of the precipitation. Also, the cold core conditions seen in the lower troposphere in the analysis are not reproduced for the $3 \mathrm{DVAR}$ run. However, values of BIAS, FAR, POD, SCORR, and RMSE with the sole exception of ETS, for the 3DVAR run confirm in a quantitative manner the improvements in the simulation of monsoon depression of 2-5 September 2006 due to assimilation of QuikSCAT surface wind data.

\subsection{Case Study 27-30 September 2006}

The monsoon depression that formed over the Bay of Bengal during 27-30 September 2006 was simulated using the WRF-ARW modeling system with and without the 3DVAR assimilation of QuikSCAT winds and the results of the above experiments are shown in this sub section. The WRF CTRL run for this case was integrated from 27 September 200600 UTC to 30 September 200600 UTC without any assimilation of observations. For the 3DVAR run, the QuikSCAT surface wind data was assimilated from 27 September 200600 UTC to 28 September 200600 UTC with a 12 hourly cycle, and the model was then subsequently integrated in a free forecast mode from 28 September 2006 00 UTC to 30 September 200600 UTC without any additional QuikSCAT observations. The model domains, model options however remained the same as in the earlier case.

The results of the model runs for the mean sea level pressure (mslp) field show a marked improvement in the simulation of the monsoon depression for 28-30 September 2006 (Fig. 14) due to the 3DVAR assimilation of QuikSCAT 
winds as can be seen from the 3DVAR mslp fields shown. The CTRL run, as seen in Fig. (14f-j), simulates a weaker system with the lowest mslp value of about $1002 \mathrm{hPa}$ while the $3 \mathrm{DVAR}$ run simulates a very active depression (Fig. 14k-o) with lowest mslp values of about $999 \mathrm{hPa}$, in good agreement with the NCEP GFS analysis fields. The center of the monsoon depression as well as its movement, originating from the east-central parts of the Bay of Bengal and movement toward the Orissa coasts during the late hours of $29^{\text {th }}$ September and early hours of $30^{\text {th }}$ September 2006 is also well simulated by the 3DVAR run.

Fig. (15) shows the profile of difference of the time averaged temperature over the depression area (of size $3^{\circ} \mathrm{x}$ $3^{\circ}$ ) and the entire domain area in Kelvin for the monsoon a) GFS-ANL 2800UTC

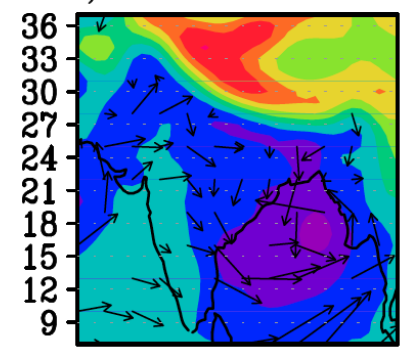

b) GFS-ANL 2812UTC

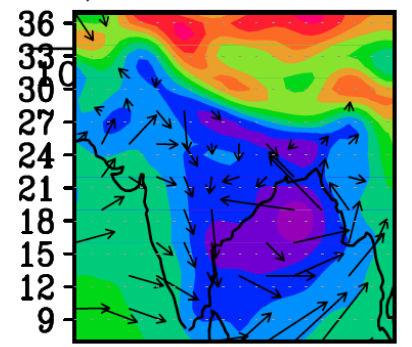

c) GFS-ANL 2900UTC

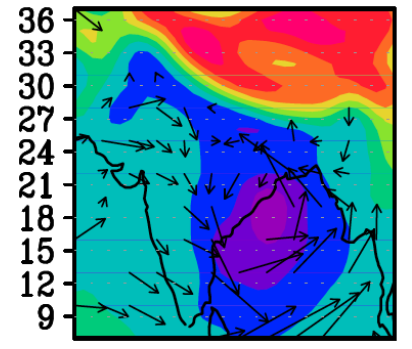

d)GFS-ANL 2912UTC

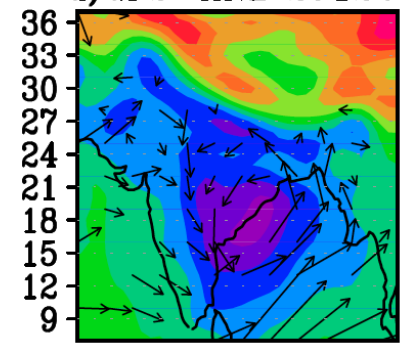

e)GFS-ANL 3000UTC

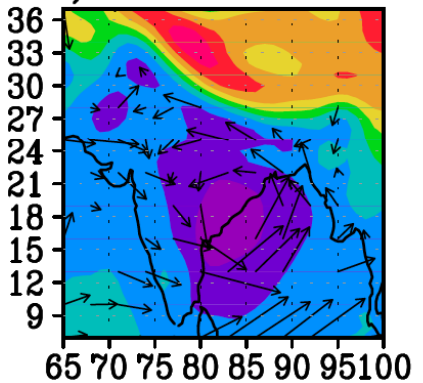

f)CTRL 2800UTC

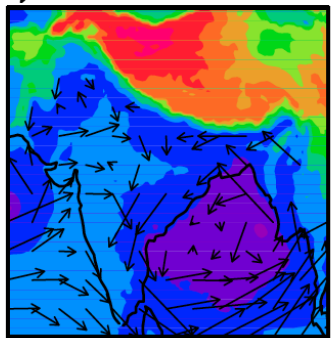

g)CTRL 2812UTC

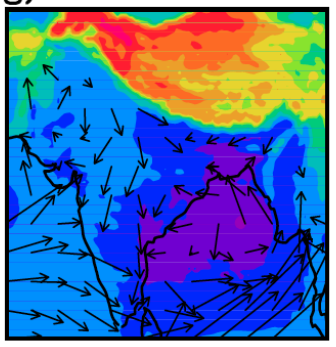

h)CTRL 2900UTC

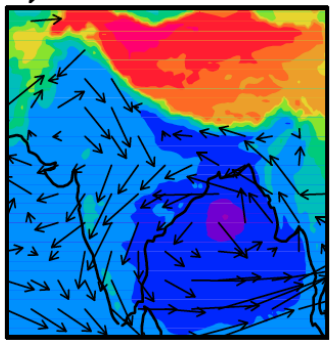

i)CTRL 2912UTC

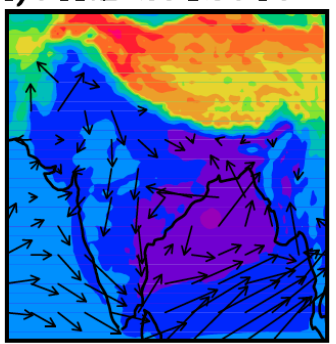

j)CTRL 3000UTC

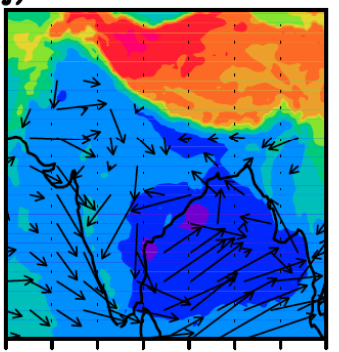

65707580859095100

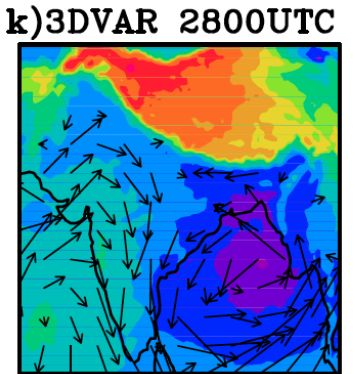

1)3DVAR 2812UTC

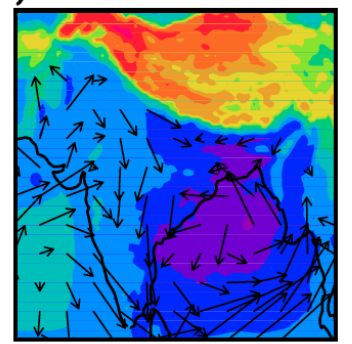

m)3DVAR 2900UTC
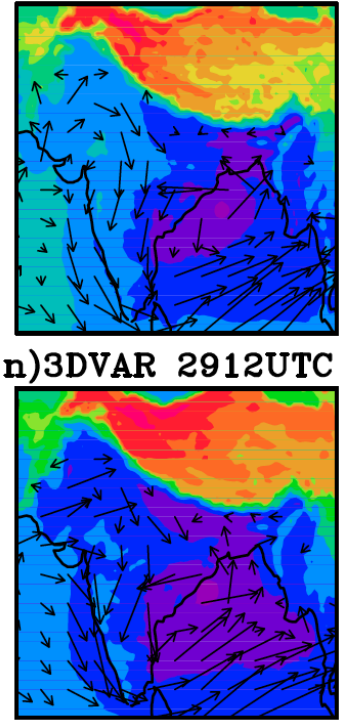

o)3DVAR 3000UTC

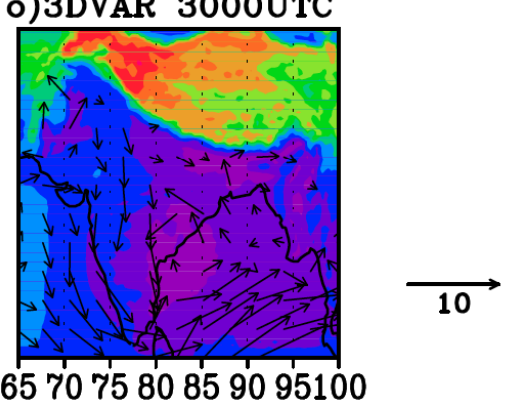

Fig. (14). Mean sea level pressure $(\mathrm{hPa}) \&$ wind vector $\left(\mathrm{ms}^{-1}\right)$ at $950 \mathrm{hPa}$ level from NCEP-GFS (a-e), CTRL (f-j) and 3DVAR (k-o) for monsoon depression of 27-30 September 2006. 
depression of 27-30 September 2006 for two model runs and GFS-ANL. Both GFS-ANL and 3DVAR runs clearly indicate the well-known thermal structure of the monsoon depressions (cold core in the lower troposphere and a warm core in the mid/upper troposphere). However, the CTRL run does not simulate a well-defined cold core structure in the lower troposphere indicating the benefits of 3DVAR assimilation of QuikSCAT winds.

Fig. (16) displays the profile of the time and area averaged relative vorticity from two model runs and GFSANL for the MD of 27-30 September 2006. Both model profiles as well as GFS-ANL profile reveal the existence of cyclonic vorticity in the lower troposphere and changing over to the anticyclonic vorticity at the upper troposphere. However, the results of the 3DVAR run are in better agreement with the GFS-ANL, in that they capture the sharp maximum of the cyclonic vorticity near $900 \mathrm{hPa}$.

Fig. (17a-f) are similar to Fig. (6a-f), except that the Fig. (17a-f) correspond to the monsoon depression that formed during the end of September 2006. For this monsoon depression, the CTRL run results (Fig. 17c, d) are somewhat bad considering the lack of agreement with TRMM of both the intensity and the spatial distribution of precipitation.

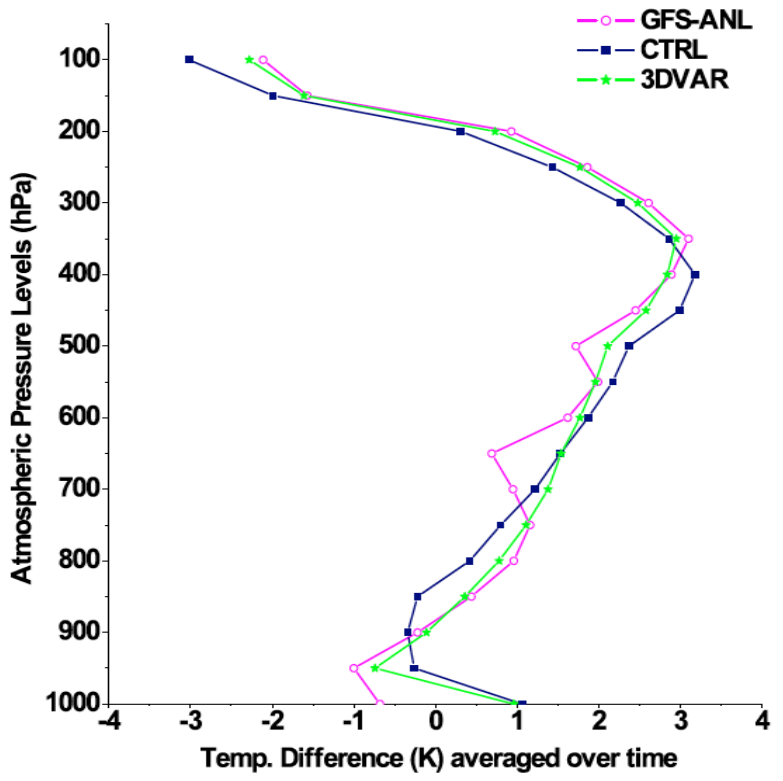

Fig. (15). Difference of Air Temperature over the depression area and the entire domain area, averaged over time, at various pressure levels in K for MD of 27-30 September 2006.

The precipitation patterns are reasonably well simulated by the 3DVAR run which is in agreement with the TRMM observations as far as the intensity of rainfall and the spatial distribution of precipitation (Fig. 17e, f) are concerned. However, the 3DVAR run does possess locational errors of the simulated maxima of the precipitation with very little rainfall over the land for both days of the forecast. It is, however, true that intense 24 hour accumulated rainfall is simulated by the 3DVAR run on both days of the forecast over the Bay of Bengal near the Orissa coast.

The results of the study for the 27-30 September 2006 monsoon depression indicate clearly that the assimilation of QuikSCAT wind data has resulted in a very marked improvement in the simulation of mean sea level pressure, wind vectors and the associated precipitation patterns, in terms of intensity and spatial distribution, although there are still errors in the location of the maximum simulated precipitation. Furthermore, the time and area averaged profile of difference of air temperature over the depression area and the environment and the profile of relative vorticity very clearly reveal that improved results have been obtained for the 3DVAR simulation using QuikSCAT observations.

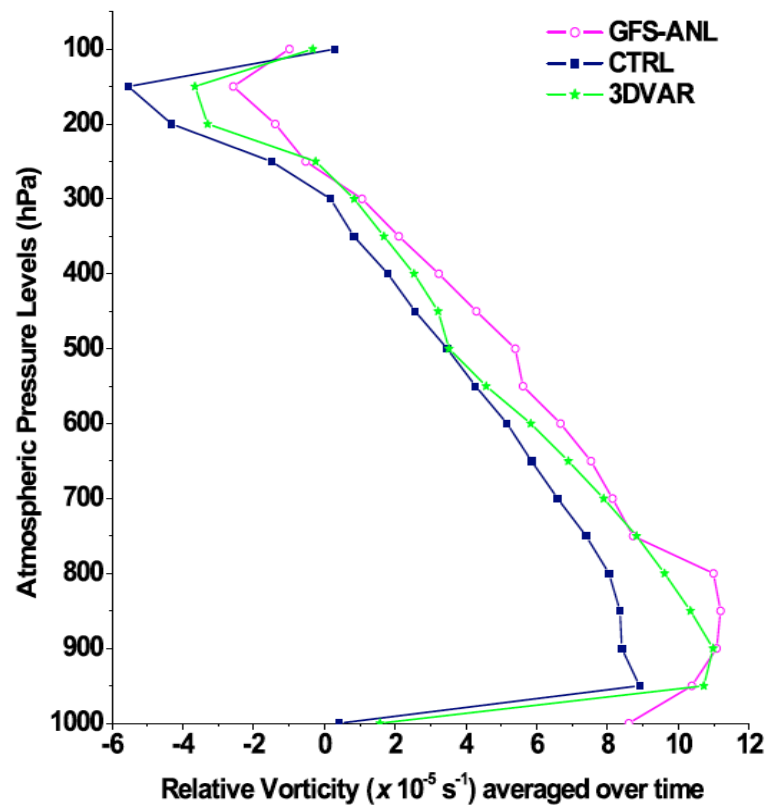

Fig. (16). Relative Vorticity (area averaged over the depression area) at various pressure levels, and averaged over time, for MD of 27-30 September 2006.

Quantitative measures of the impact of 3DVAR assimilation of QuickSCAT surface wind data, in terms of BIAS, FAR, POD, and ETS are calculated, as before, for the simulated rainfall of two model runs with respect to TRMM for the monsoon depression of 27-30 September 2006 and are shown in Figs. (18-21), respectively.

Both model runs (Fig. 18) show some underestimation of the rainfall for all threshold rainfalls with the 3DVAR run showing more underestimation. Also, the underestimation (Fig. 18) for both model runs does increase with the increasing threshold rainfalls. The false alarm ratio consistently shows lower values (Fig. 19) for the 3DVAR run for all rainfall thresholds as compared to the CTRL run. Also, the FAR values increase with the increase in the rainfall thresholds for both model runs. The 3DVAR run has a slightly higher POD value (Fig. 20) as compared to the CTRL run for all threshold rainfalls except for $20 \mathrm{~mm}$ threshold value. Also, the POD value decreases with the increase in the rainfall thresholds for both model runs, indicating difficulty in the accurate prediction of heavy and very heavy rainfall events.

The reason for the lack of substantial improvement in the POD values for the 3DVAR run for this case, as compared to the earlier case is due to the larger underestimation of the 3DVAR run. Thus despite, a lower value of FAR, the increase in the POD values for the $3 \mathrm{DVAR}$ run in this case is 
a) $\operatorname{TRMM}(200609-2900 \mathrm{UTC})$

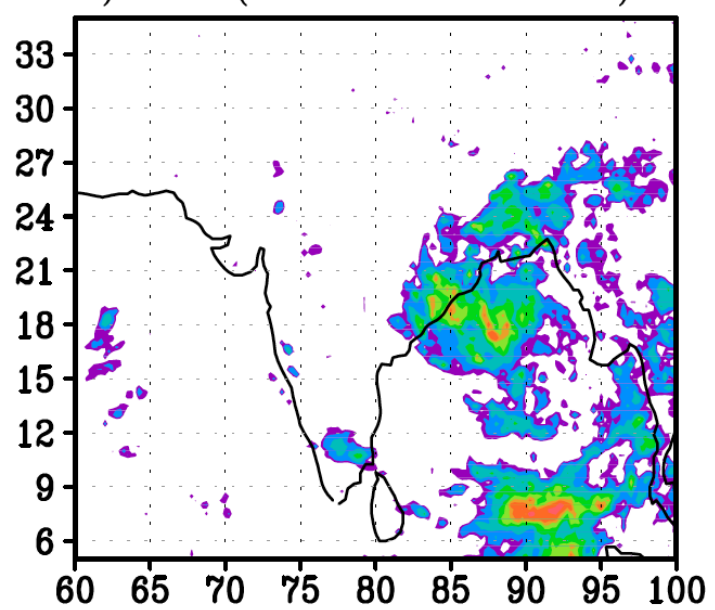

c) CTRL(200609-2900UTC)

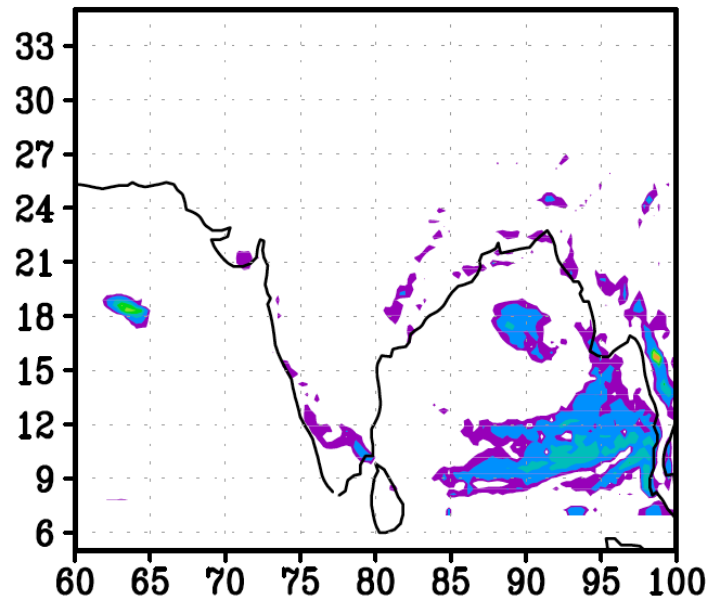

e)3DVAR(200609-2900UTC)

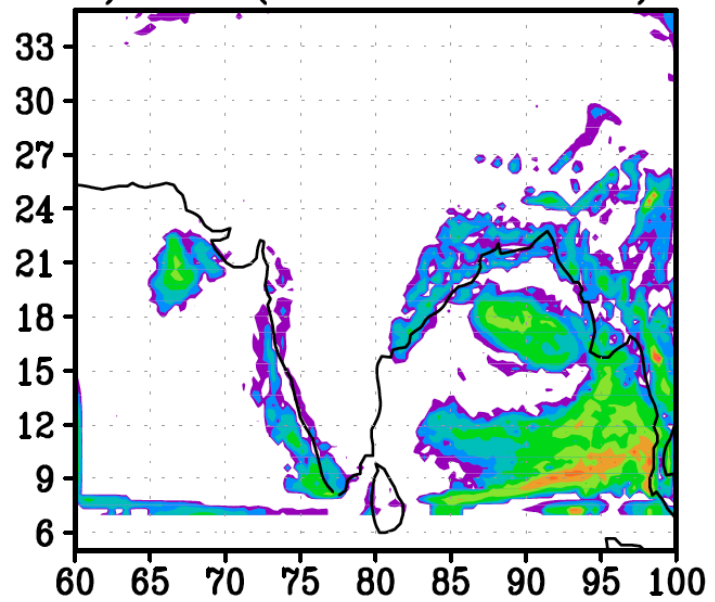

b) $\operatorname{TRMM}(200609-3000 \mathrm{UTC})$

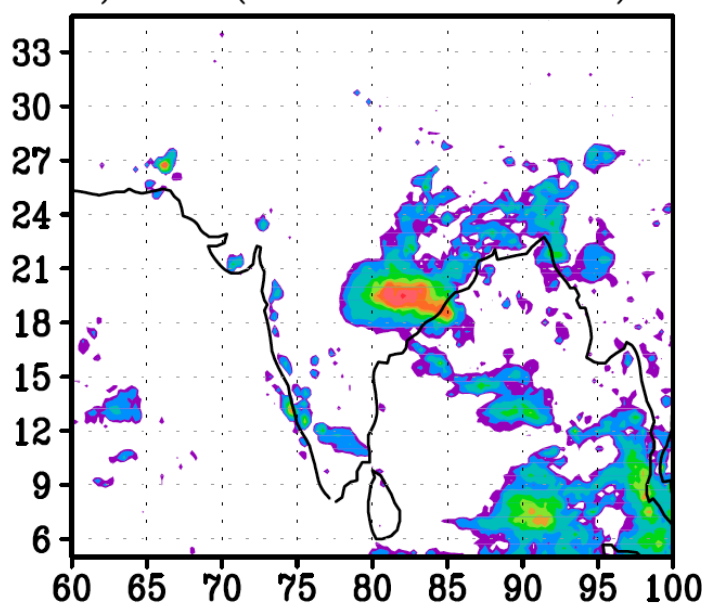

d)CTRL(200609-3000UTC)

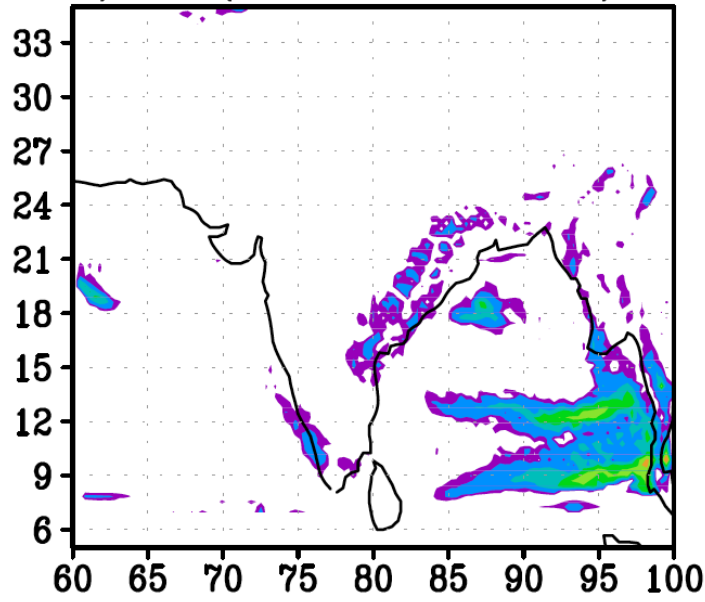

f)3DVAR(200609-3000UTC)

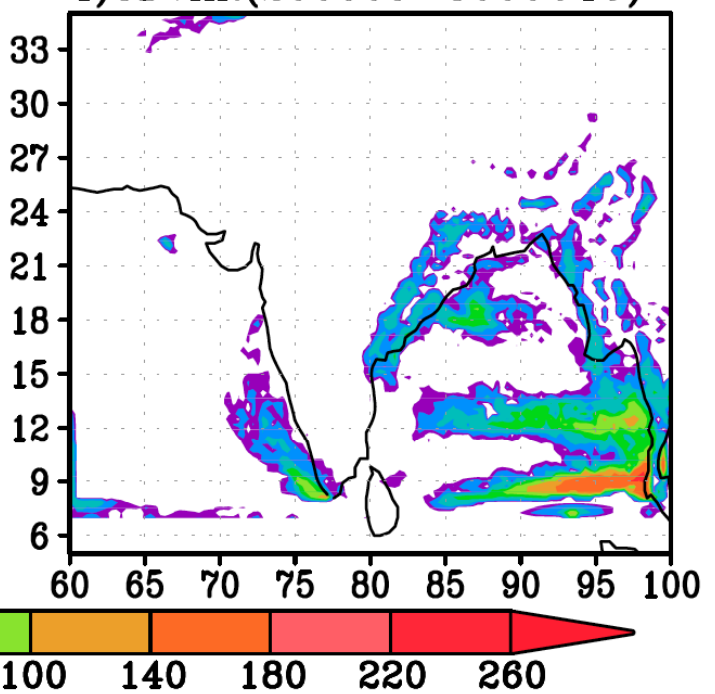

Fig. (17). 24 hrs accumulated precipitation (mm) patterns for the first two days of the forecast from TRMM (a, b), CTRL (c, d) and 3DVAR (e, f) for monsoon depression of 27-30 September 2006.

not significant. However, this is offset to a great extent by the consistent increase in the ETS value of the 3DVAR run as compared to the CTRL run for all rainfall thresholds (Fig. 21). Also, the ETS values, like the POD values, show a decreasing trend with the increase in the rainfall thresholds illustrating the general difficulty of accurately predicting the very heavy rainfall events. 


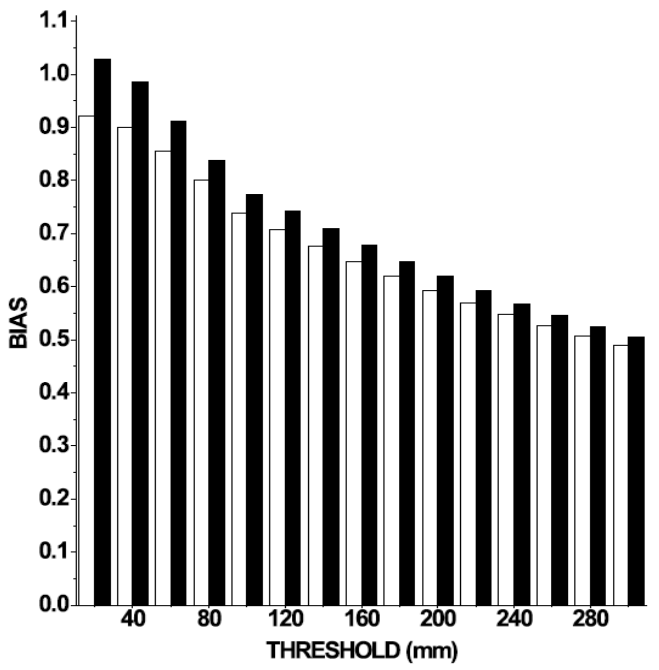

Fig. (18). BIAS for CTRL (filled bars) and 3DVAR (unfilled bars) simulations of MD of 27-30 Sept. 2006 for different rainfall thresholds.

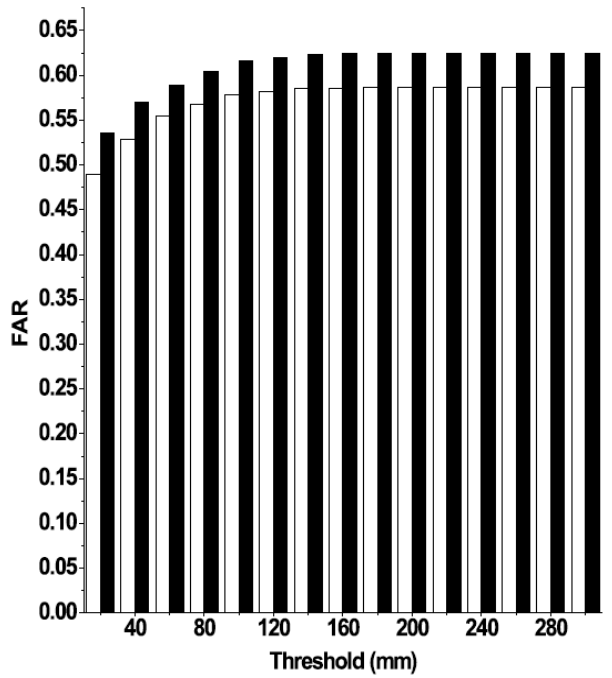

Fig. (19). FAR for CTRL (filled bars) and 3DVAR (unfilled bars) simulations of MD of 27-30 Sept. 2006 for different rainfall thresholds.

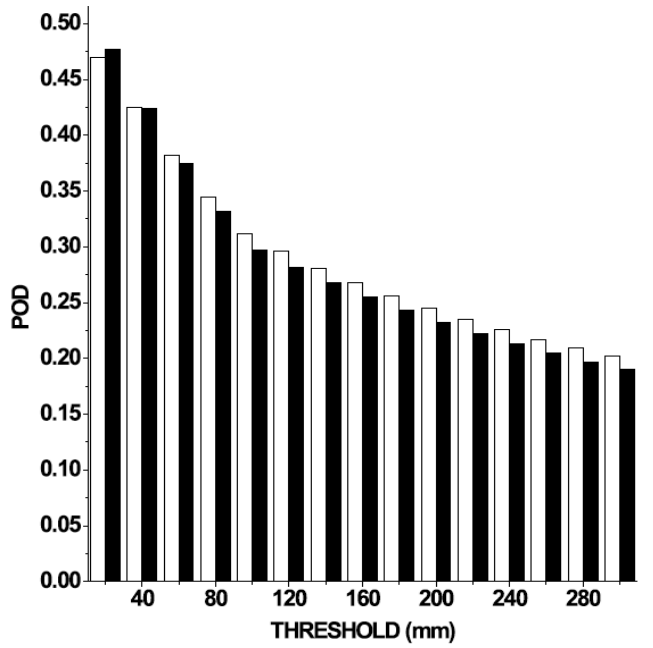

Fig. (20). POD for CTRL (filled bars) and 3DVAR (unfilled bars) simulations of MD of 27-30 Sept. 2006 for different rainfall thresholds.

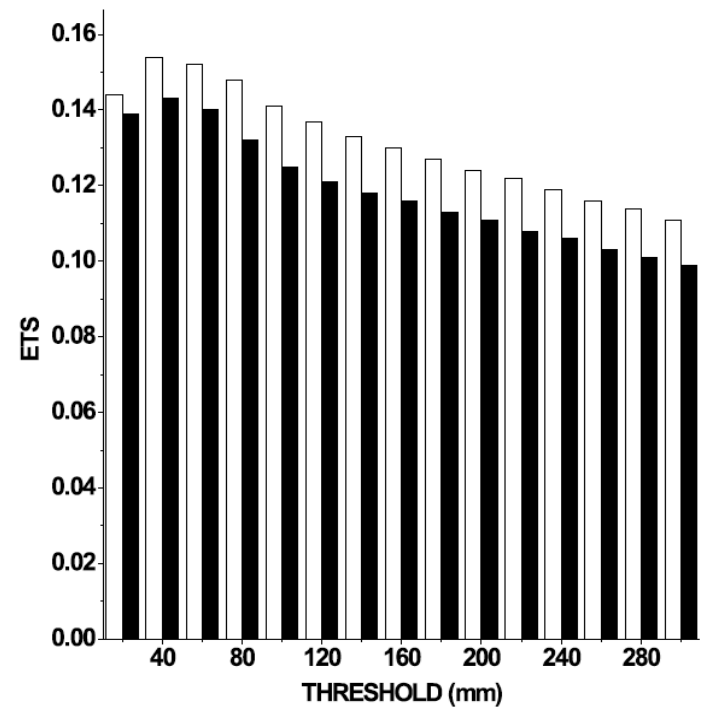

Fig. (21). ETS for CTRL (filled bars) and 3DVAR (unfilled bars) simulations of MD of 27-30 Sept. 2006 for different rainfall thresholds.

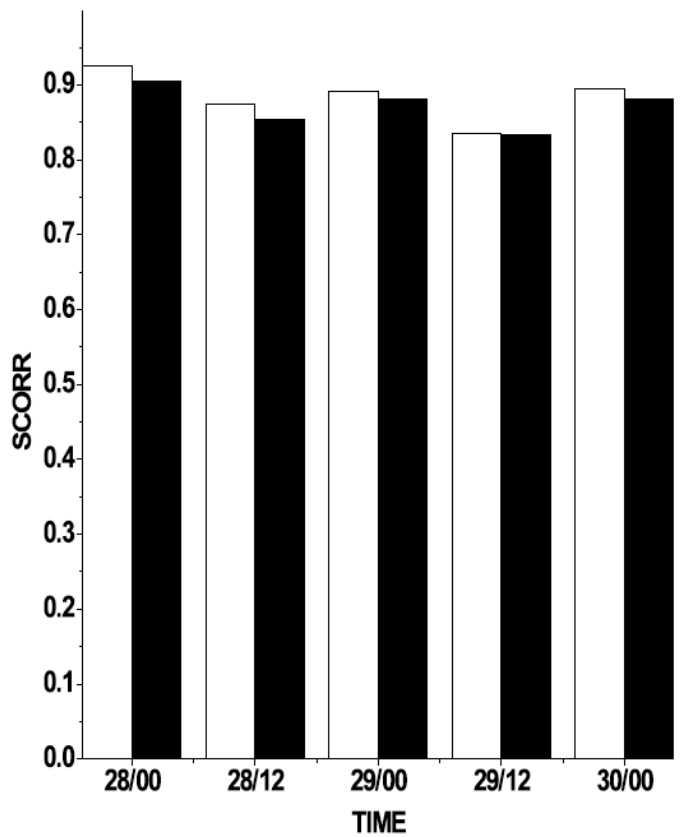

Fig. (22). SCORR for mslp for CTRL (filled bars) and 3DVAR (unfilled bars) simulations of MD of 27-30 Sept. 2006.

Further quantitative measures such as the SCORR for mslp and the RMSE for area-averaged wind $\left(75^{\circ} \mathrm{E}-95^{\circ} \mathrm{E}\right.$, $10^{\circ} \mathrm{N}-30^{\circ} \mathrm{N}$ ) at $950 \mathrm{hPa}$ are calculated as before for the present case with respect to the GFS analysis and are shown in Figs. $(\mathbf{2 2}, \mathbf{2 3})$, respectively. The SCORR values are slightly higher for the 3DVAR run as compared to the CTRL run for all times. The above result (Fig. 22) is consistent with Fig. (14) which showed a better simulation of the depression center and its movements for the 3DVAR run. The RMSE for wind speed at $950 \mathrm{hPa}$ shows lower values for the 3DVAR run as compared to the CTRL run except for the period during the late hours of day two of the forecast when the simulated depression was weakening (Fig. 23).

Values of BIAS, FAR, POD, ETS, SCORR, and RMSE for the CTRL run and the 3DVAR run and their quantitative 
comparison well confirm in a quantitative manner the improvements in the simulation of the monsoon depression of 27-30 September 2006 due to assimilation of QuikSCAT surface wind data.

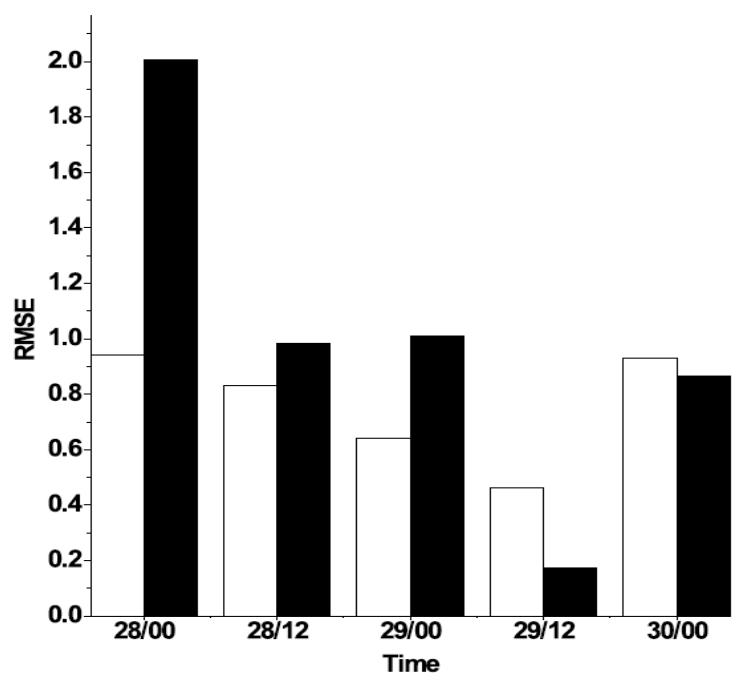

Fig. (23). RMSE in $\mathrm{m} \mathrm{s}^{-1}$ for area-averaged wind at $950 \mathrm{hPa}$ for CTRL (filled bars) and 3DVAR (unfilled bars) simulations of MD of 27-30 Sept. 2006.

\section{CONCLUSION}

The impact of assimilating surface wind observations over the Indian seas from the QuikSCAT using 3DVAR assimilation technique in the WRF model is investigated in this study by simulating two monsoon depressions of September 2006 over the Indian region. The results of the simulations with and without QuikSCAT are compared with one another and also with observations.

For the case of the monsoon depression that formed during 2-5 September 2006, the 3DVAR simulations for the mean sea level pressure and the lower tropospheric winds indicate improved patterns which are in agreement with GFS-ANL fields as compared to the CTRL run. However, both runs, despite reproducing the observed intensity on day one of the forecast, fail to correctly simulate the location of the maximum simulated precipitation for both the days. Hence the assimilation of QuikSCAT data has, therefore, exhibited mixed results for the simulated precipitation for the 2-5 September 2006 depression. The results for the profiles of air temperature difference and the relative vorticity also provide good evidence of the improved results due to 3DVAR assimilation of QuikSCAT observations. The values of BIAS, FAR, POD and ETS at different rainfall thresholds along with the SCORR and RMSE for both runs confirm the improvement in the simulation of monsoon depression due to the assimilation of QuikSCAT surface wind data. The 3DVAR run consistently shows lower BIAS, lower false alarm ratio and higher probability of detection for all rainfall thresholds as compared to the CTRL run. The SCORR values are higher for the first day in case of the 3DVAR run results while the RMSE for area averaged wind at $950 \mathrm{hPa}$ shows lower values for the 3DVAR run as compared to the CTRL run.

For the case of the monsoon depression that formed during 27-30 September 2006, the 3DVAR simulations for the mean sea level pressure and the lower tropospheric winds indicate marked improvements by simulating a very active depression consistent with the observed movement. Furthermore, the simulated precipitation of the CTRL run for this case is somewhat bad in terms of both the intensity and spatial distribution of precipitation. However, the 3DVAR run simulates extensive precipitation in good agreement with TRMM, albeit with some locational errors of the simulated maximum precipitation. Furthermore, the profiles of air temperature difference and the relative vorticity clearly show improved results for the 3DVAR QuikSCAT assimilation run. Also, values of BIAS, FAR, POD and ETS at different rainfall thresholds along with the SCORR, and RMSE for both runs show clear improvements in the simulation of monsoon depression due to assimilation of QuikSCAT surface wind data. The 3DVAR run consistently shows lower BIAS (higher underestimation here), lower FAR, higher POD and higher ETS for all rainfall thresholds as compared to the CTRL run. Also, the 3DVAR SCORR values are higher for the first day while for the 3DVAR run, the RMSE for area averaged wind at $950 \mathrm{hPa}$ shows lower values as compared to the CTRL run.

In the context of the earlier studies on data assimilation by other researchers over the Indian region, our current study is performed with the objective of ingesting QuikSCAT surface wind observations only for two monsoon depressions. It is to be noted that in this study only the QuikSCAT surface wind observations over the sea are ingested for a 24 hour pre-forecast period. The study exclusively focuses on the spatial structure of the MDs and the movement of the MDs over the Bay of Bengal and the Indian region, which have been qualitatively and quantitatively analyzed in terms of distribution of mean sea level pressure (mslp) fields as well as spatial correlation of the simulated mslp fields with respect to that of GFS-ANL. The results of this study also include the atmospheric profile of area-averaged and time-averaged air temperature difference obtained over the depression area and the environment as well as the atmospheric profile of areaaveraged and time-averaged relative vorticity and these are compared with the respective GFS analysis. Furthermore, the quantitative measure of model performance for the simulated precipitation in terms of various skill scores is also examined in detail.

The highlights of the results obtained in our study have following features. A dramatic impact in the simulation is not expected with the assimilation of surface wind information over the seas, which is also not available at frequent intervals. Despite the above, there is a clear and marked impact of ingesting the QuikSCAT data for the depression that formed during 27-30 September 2006 while the improvement is slight for the other depression that formed during 2-5 September 2006. Also, the 3DVAR run shows that the cold core in the lower troposphere as well as the cyclonic vorticity profile is better simulated in terms of closer agreement with the GFS-ANL results. Consistent with the above observations, there is a also a clear improvement in the quantitative measures of the skill scores with lower BIAS, lower false alarms and higher probability of detection for all rainfall thresholds for the model run which has assimilated the QuikSCAT observations. 


\section{ACKNOWLEDGEMENTS}

QuikSCAT data were obtained from NASA while the precipitation data were got onboard TRMM satellite. WRF and 3DVAR are obtained from NCAR (National Centre for Atmospheric Research) and NCEP-GFS fields are obtained from NCEP. The first author gratefully acknowledges University Grants Commission (UGC) - Council for Scientific and Industrial Research (CSIR) for providing a Research Fellowship. The second author acknowledges funding support from the Oceansat-2 Utilization Project and INSAT3D projects of the Space Application Centre, Indian Space Research Organization, Ahmedabad, India and the Defense Research and Development Organization, India.

\section{REFERENCE}

[1] Sikka DR. Some aspects of life history, structure and movement of monsoon depression. Pure Appl Geophys Basel 1977; 115: 150129.

[2] Das AK, Mohanty UC, Das S, Mandal M, Kalsi SR. Circulation characteristics off a monsoon depression during BOBMEX-99 using high-resolution analysis. Proc Indian Acad Sci (Earth \& Planet Sci) 2003; 112: 165-84.

[3] Xavier VF, Chandrasekar A, Rahman H, Niyogi D, Alapaty K. The effect of satellite and conventional meteorological data assimilation on the mesoscale modeling of monsoon depressions over India. Meteorol Atmos Phys 2008. DOI: 10.1007/s00703-008-0314-7.

[4] Barker DM, Huang W, Guo YR, Bourgeois AJ, Xiao QN. A ThreeDimensional Variational Data Assimilation System for MM5: Implementation and Initial Results. Mon Wea Rev 2004; 132: 897914.

[5] Courtier P, Andersson E, Heckley W, et al. The ECMWF implementation of three-dimensional variational assimilation (3DVar). I: Formulation 1998; 124: 1783-808.

[6] Skamarock WC, Klemp JB, Dudhia J, et al. A Description of the advanced research WRF version 2. NCAR Technical Note 2005; NCAR/TN-468+STR: 88 .

[7] Barker DM, Huang W, Guo YR, Bourgeois AJ. A threedimensional variational (3DVAR) data assimilation system for use with MM5. NCAR Technical Note 2003; NCAR/TN-453+STR: 68.

[8] Hu M, Xue M, Gao J, Brewster K. 3DVAR and cloud analysis with WSR-88D level-II data for the Prediction of the Fort Worth, Texas, Tornadic Thunderstorms. Part II: Impact of radial velocity analysis via 3DVAR. Mon Wea Rev 2006; 134: 699-721.

[9] Rakesh V, Singh R, Joshi PC: Intercomparison of the performance of MM5/WRF with and without satellite data assimilation in shortrange forecast applications over the Indian region. Meteorol Atmos Phys 2009; 105: 133-55.

[10] Lorenc AC, Ballard SP, Bell RS, et al. The Met. Office global three-dimensional variational data assimilation scheme. Quart J Roy Meteor Soc 2000; 126: 2991-3012.
[11] Zou X, Vandenberghe F, Pondeca M, Kuo YH. Introduction to adjoint techniques and the MM5 adjoint modeling system. NCAR Tech. Note 1997; NCAR/TN-435+STR: 110. [Available from UCAR Communications, P.O. Box 3000, Boulder, CO, USA 80307.]

[12] Ide K, Courtier P, Ghil M, Lorenc AC. Unified notation for data assimilation: Operational, sequential and variational. J Met Soc Jap 1997; 75: 181-89.

[13] Lorenc AC. Analysis methods for numerical weather prediction. Quart. J Roy Meteor Soc 1986; 112: 1177-94.

[14] Chelton DB, Freilich MH, Sienkiewicz JM, Von Ahn JM. On the Use of QuikSCAT Scatterometer Measurements of Surface Winds for Marine Weather Prediction. Mon Wea Rev 2006; 134: 2055207.

[15] Leslie LM, Buckley BW. Comments on "Scatterometer-based assessment of $10-\mathrm{m}$ wind analyses from the operational ECMWF and NCEP numerical weather prediction models." Mon Wea Rev 2006; 134: 737-42

[16] Gaiser PW, Coauthors. The WindSat spaceborne polarimetric microwave radiometer: Sensor description and early orbit performance. IEEE Trans Geosci Remote Sens 2004; 42: 2347-61.

[17] Freilich MH, Vanhoff BA. The accuracy of the preliminary WindSat vector wind measurements: Comparisons with NDBC buoys and QuikSCAT. IEEE Trans Geosci Remote Sens 2006; 44 622-37.

[18] Monaldo FM. Evaluation of WindSat wind vector performance with respect to QuikSCAT estimates. IEEE Trans. Geosci Remote Sens 2006; 44: 638-44.

[19] Chen SH. The Impact of assimilating SSM/I and QuikSCAT Satellite Winds on Hurricane Isidore Simulations. Mon Wea Rev 2007; 135: 549-66.

[20] Govindankutty M, Chandrasekar A, Bohra AK, George JP, Gupta MD. The Impact of assimilation of MODIS Observations using WRF-VAR for the prediction of a monsoon depression during September 2006. Open Atmos Sci J 2008; 2: 68-78.

[21] Vinodkumar, Chandrasekar A, Alapaty K, Niyogi D. The effect of a surface data assimilation technique and the traditional fourdimensional data assimilation for the prediction of a monsoon depression over India using a mesoscale model. Natl Hazards 2007; DOI 10.1007/s11069-006-9080-3

[22] Vinodkumar, Chandrasekar A, Alapaty K, Niyogi D. The impacts of indirect soil moisture assimilation and direct surface temperature and humidity assimilation on a mesoscale model simulation of an Indian monsoon depression. J Appl Meteorol Climatol 2008; 47: 1393-412.

[23] Agrawal N, Sharma R, Basu SK, Sarkar A, Agrawal VK. Evaluation of relative performance of QuikSCAT and NCEP reanalysis winds through simulations by an OGCM. Deep-Sea Res 2007; 54: 1311-28

[24] Staudenmaier MJ. Precipitation verification statistics from the NCEP operational model suite. Western region technical attachment no. 96-28 1996.

[25] Persson A, Grazzini F. User guide to ECMWF forecast products 4.0. 2007; 72-73. 